\title{
Testing for the 'predictability' of dynamically triggered earthquakes in The Geysers geothermal field
}

\author{
Aiken Chastity ${ }^{1,2,{ }^{*}}$, Meng Xiaofeng ${ }^{3,4,5}$, Hardebeck Jeanne ${ }^{6}$ \\ ${ }^{1}$ The University of Texas at Austin, Institute for Geophysics, Austin, TX, United States \\ ${ }^{2}$ IFREMER, Marine Geosciences - LAD, Plouzané, France \\ ${ }^{3}$ University of Washington, Department of Earth and Space Sciences, Seattle, WA, United States \\ ${ }^{4}$ University of Washington, eScience Institute, Seattle, WA, United States \\ ${ }^{5}$ Southern California Earthquake Center, University of Southern California, Los Angeles, CA, United \\ States \\ ${ }^{6}$ U.S. Geological Survey, Menlo Park, CA, United States \\ * Corresponding author : Chastity Aiken, email address : chastity.aiken@ifremer.fr
}

\begin{abstract}
:
The Geysers geothermal field is well known for being susceptible to dynamic triggering of earthquakes by large distant earthquakes, owing to the introduction of fluids for energy production. Yet, it is unknown if dynamic triggering of earthquakes is 'predictable' or whether dynamic triggering could lead to a potential hazard for energy production. In this paper, our goal is to investigate the characteristics of triggering and the physical conditions that promote triggering to determine whether or not triggering is in anyway foreseeable. We find that, at present, triggering in The Geysers is not easily 'predictable' in terms of when and where based on observable physical conditions. However, triggered earthquake magnitude positively correlates with peak imparted dynamic stress, and larger dynamic stresses tend to trigger sequences similar to mainshock-aftershock sequences. Thus, we may be able to 'predict' what size earthquakes to expect at The Geysers following a large distant earthquake.
\end{abstract}

\section{Highlights}

Template matching event detection enhances statistical triggering test quality. Maximum triggered earthquake size positively correlates with dynamic stress. However, when and where triggering will occur is not easily 'predictable'.

Keywords : dynamic triggering, template matching, earthquake, stress changes, The Geysers 
Passing seismic waves of large earthquakes can initiate seismic activity at remote

62 distances either directly or indirectly, a phenomenon commonly known as dynamic triggering

63 [Hill and Prejean, 2015]. Transient stresses on the order of a few kilopascals generated by large,

64 distant earthquakes are known to dynamically trigger icequakes [Peng et al., 2014], deep tectonic

65 tremor [e.g., Aiken et al., 2013], and shallow microearthquakes [e.g. Hill et al., 1993]. The

66 general understanding is that triggered seismicity is "clock-advanced", in that it occurs as a result

67 of these small transient stresses loading an active fault and pushing it toward failure [e.g.,

68 Dietrich, 1994; Gomberg, 2010]. Recent models of transient stress loading on active faults have

69 indicated that triggering can be somewhat predictable, given certain information about the source

70 of the stresses and information about the receiving fault [Hill, 2012; Gonzalez-Huizar and

71 Velasco, 2011]. Thus, future earthquake rate increases due to transient stressing could possibly

72 be predicted, if the conditions under which failure occurs are better understood [Brodsky and van

73 der Elst, 2014].

74 Regions with high background activity are known to be most susceptible to dynamic

75 triggering [Hill and Prejean, 2015; Aiken and Peng, 2014]. The Geysers geothermal field,

76 located in northern California, is an extremely active fault system compared to other geothermal 
77 areas in California. Even when considering only events with magnitude $(M) \geq 2$, The Geysers

78 produced more earthquakes than other active geothermal fields in California combined over the

79 last 15 years (Figure S1). In addition, large distant earthquakes have repeatedly triggered The

80 Geysers [Prejean et al., 2004; Brodsky, 2006; Aiken and Peng, 2014], making it a favorable

81 region for exploring the characteristics of triggering and the conditions under which dynamic

82 triggering of microearthquakes occurs.

83 In this study, we expand upon the systematic triggering analysis conducted by Aiken and

84 Peng [2014]. In that work, small magnitude earthquakes $(M<4)$ triggered in The Geysers were

85 identified by visual inspection and compared to network-detected catalogs. Here, we apply the

86 matched filter technique (Section 2) with the intention to further improve the catalog

87 completeness for statistical tests. We search for key characteristics that could possibly explain

88 the conditions that promote dynamic triggering of earthquakes, which include seismicity rates

89 (Section 3), spatial extent and degree of triggering (Section 4), fault orientation dependence on

90 triggering (Section 5), and The Geysers' stress state prior to mainshocks and during triggering

91 (Section 6).

92

\section{2. Data and methods}

\section{$94 \quad 2.1$ Mainshock selection}

95 Aiken and Peng [2014] identified 10 large, distant mainshocks that triggered

96 microearthquakes in The Geysers, based on statistically significant increased rate changes after

97 the mainshocks. In each of those cases, microearthquakes $(M<4)$ with $S-P$ time $<10$ seconds

98 were hand-picked using 3-component waveform envelopes from a small number of stations.

99 Here, we re-examine these same triggering mainshocks and also investigate triggering by 15 
100 additional mainshocks. Namely, we select repeating $M \geq 5$ earthquakes from offshore northern

101 California, which Aiken and Peng [2014] suggested to be a possible repeating dynamic triggering

102 source, and the August 24, 2014 M6 South Napa earthquake which occurred $\sim 80$ km southeast of

103 The Geysers (Figure 1). Our study time period is limited to 2001 to early 2015. A complete list

104 of triggering sources (mainshocks) we investigate in this study can be found in Table 1, each of

105 which is reported in the Advanced National Seismic Systems (ANSS, a.k.a. ComCat) earthquake

106 catalog available from the Northern California Earthquake Data Center (NCEDC). Mainshocks

107 that are possibly repeat triggering sources from the Mendocino Triple Junction (MTJ) are listed

108 in Group 2 of Table 1; all other events are in Group 1.
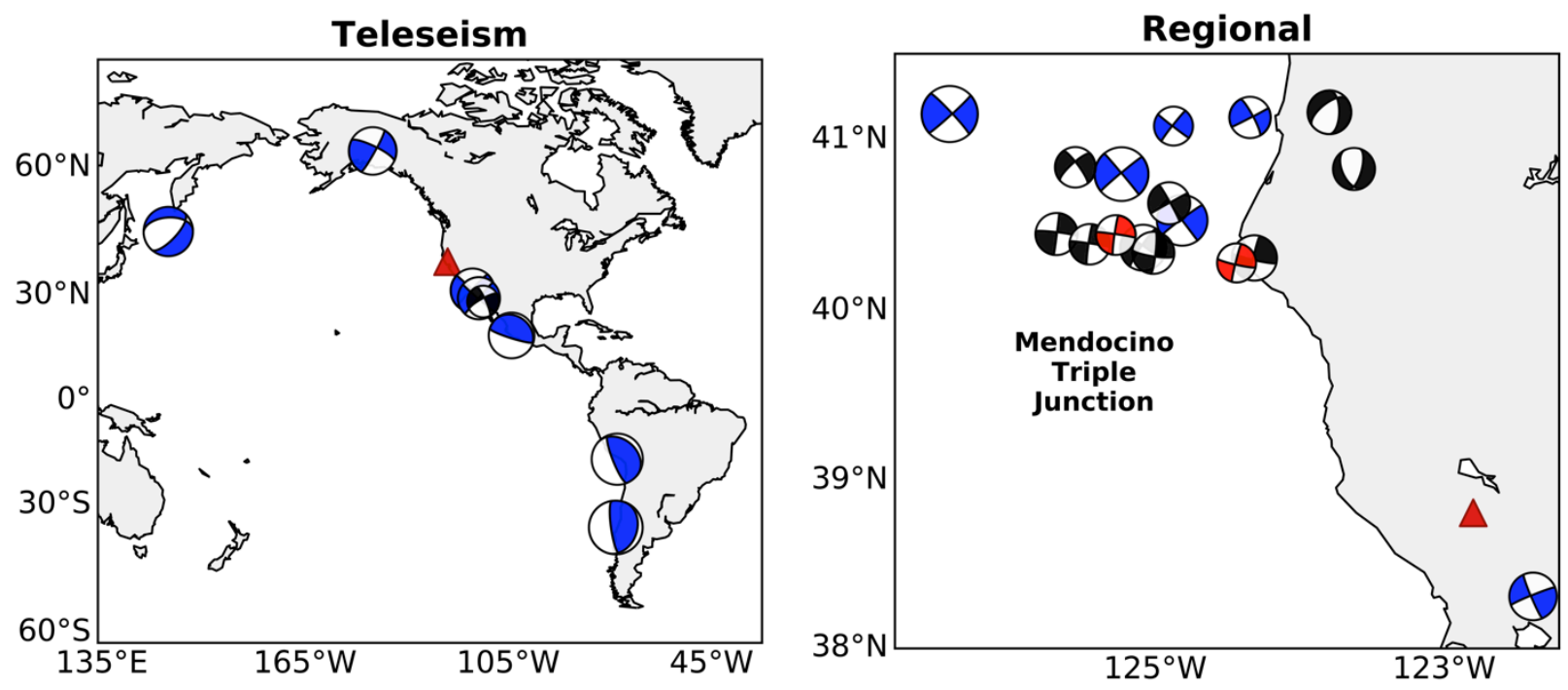

110 Figure 1. Map illustrating focal mechanisms of triggering (blue) and non-triggering (black) 111 mainshocks (see Section 2) at teleseismic distances (left) and regional distances (right). Two 112 other non-triggering mainshocks in this study did not have reported focal mechanisms (red). We 113 assigned these two events mechanisms similar to their nearest neighbors. Size of the focal 114 mechanisms corresponds to magnitude (Table 1). The center of The Geysers seismicity is 115 marked by a red triangle.

116

Table 1. Potentially triggering mainshocks investigated in this study.

$\bar{z}=$\begin{tabular}{cclcl} 
Date & Time & Region* & $M^{* *}$ & Study \\
\hline $06 / 23 / 2001$ & $20: 33: 14$ & southern Peru & 8.1 & Aiken and Peng [2014]
\end{tabular}




\begin{tabular}{|c|c|c|c|c|}
\hline $11 / 03 / 2002$ & $22: 12: 42$ & Denali, AK & 7.9 & Prejean et al. [2004]; Aiken and Peng [2014] \\
\hline $01 / 22 / 2003$ & $02: 06: 35$ & Colima, MX & 7.6 & Aiken and Peng [2014] \\
\hline 01/04/2006 & $08: 32: 32$ & Gulf of CA & 6.6 & Aiken and Peng [2014] \\
\hline 01/13/2007 & $04: 23: 21$ & Kuril Islands & 8.1 & Aiken and Peng [2014] \\
\hline 08/03/2009 & $17: 59: 56$ & Baja CA & 6.9 & Aiken and Peng [2014] \\
\hline $04 / 04 / 2010$ & $22: 40: 42$ & Baja CA & 7.2 & Aiken and Peng [2014] \\
\hline $02 / 27 / 2010$ & $06: 34: 12$ & Maule, Chile & 8.8 & Aiken and Peng [2014] \\
\hline 08/24/2014 & $10: 20: 44$ & Napa, CA & 6.0 & This study \\
\hline 09/20/2001 & $08: 02: 23$ & MTJ & 5.1 & This study \\
\hline 06/17/2002 & $16: 55: 08$ & MTJ & 5.2 & This study \\
\hline 08/15/2003 & $09: 22: 15$ & MTJ & 5.3 & This study \\
\hline 06/15/2005 & $02: 50: 54$ & MTJ & 7.2 & Brodsky [2006]; Aiken and Peng [2014] \\
\hline 07/19/2006 & $11: 41: 43$ & MTJ & 5.0 & This study \\
\hline $02 / 26 / 2007$ & $12: 19: 54$ & MTJ & 5.4 & This study \\
\hline 05/09/2007 & 07:50:04 & MTJ & 5.2 & This study \\
\hline $06 / 25 / 2007$ & $02: 32: 25$ & MTJ & 5.0 & This study \\
\hline 04/30/2008 & 03:03:07 & MTJ & 5.4 & This study \\
\hline $01 / 10 / 2010$ & $00: 27: 39$ & MTJ & 6.5 & Aiken and Peng [2014] \\
\hline 02/04/2010 & $20: 20: 22$ & MTJ & 5.9 & This study \\
\hline 02/13/2012 & 21:07:03 & MTJ & 5.6 & Aiken and Peng [2014] \\
\hline 07/21/2012 & $01: 52: 02$ & MTJ & 5.1 & This study \\
\hline 03/10/2014 & $05: 18: 13$ & MTJ & 6.8 & Aiken and Peng [2014] \\
\hline $01 / 01 / 2015$ & $12: 16: 15$ & MTJ & 5.3 & This study \\
\hline $01 / 28 / 2015$ & $21: 08: 54$ & MTJ & 5.7 & This study \\
\hline
\end{tabular}

\section{$118 \quad 2.2$ Matched filter analysis}

119 We roughly follow the method of Meng et al. [2013] for detecting microearthquakes

120 occurring in The Geysers around the times of each mainshock (Table 1) using the matched filter

121 technique and briefly summarize our approach here. We utilize 17 seismic stations surrounding

122 The Geysers (Table S1). For each station, we retrieve the vertical component continuous seismic

123 waveforms half a day before to 1 day after each triggering mainshock from the NCEDC. This

124 detection time is larger than that of Aiken and Peng [2014], where microearthquakes occurring \pm

1255 hours within the mainshock were identified by visual inspection. For each mainshock, we 
126 select a total of 3,000 local earthquakes around its origin time from the ANSS/ComCat

127 earthquake catalog and retrieve the vertical component seismic waveforms 0.5 seconds before

128 and 3.5 seconds after each templates' $P$ - or $S$-wave pick, whichever is available. These 3,000

129 events are used as template events for scanning through continuous waveforms during the

130 matched filter analysis. The time windows for selecting the template events from the NCEDC

131 earthquake catalog can be found in Table S2.

132 We next apply a 5 to $15 \mathrm{~Hz}$ band-pass filter to both continuous and template waveforms

133 to enhance local earthquake signals and then down-sample the waveforms to $40 \mathrm{~Hz}$ to reduce

134 computation time. On each channel, we compute the normalized cross-correlation between a

135 single template and continuous waveforms at all data points, where the move-out of the template

136 is fixed at each channel. Then, the correlation coefficients are shifted back by the negative of the

137 move-out at each channel, and correlation traces from all channels are stacked into a mean cross-

138 correlation trace, which increases the signal to noise ratio of small magnitude events. The event

139 detection threshold is set as the sum of median value and 9 times the median absolute deviation

140 from the mean correlation trace [e.g., Shelly et al., 2007; Peng and Zhao, 2009; Meng et al.,

141 2013]. With this detection threshold, we assign the hypocenters of detected events to be the same

142 as that of the template. In doing so, the location uncertainty of the detected events is generally on

143 the order of a few kilometers [Peng and Zhao, 2009]. Since we mainly focus on the temporal

144 evolution of seismicity rate within the Geysers, the location uncertainty should not greatly affect

145 our observations. We compute the magnitudes of detected events as follows:

146

$$
M_{\text {detected }}=M_{\text {template }}+\frac{1}{c} \log _{10} R
$$

147 where $M_{\text {detected }}$ and $M_{\text {template }}$ is magnitude for the detected event and template, respectively, $c$ is a 148 constant, and $R$ is the median peak amplitude ratio between the detected event and template 
149 among all channels. Following previous studies [Peng and Zhao, 2009; Meng et al., 2013; Schaff

150 and Richards, 2014], we simply take the approximate $c$ value as 1 . We repeat this process for all

151 templates. When multiple templates detect the same event (i.e., origin times of detected events

152 have a separation time of less than 2 seconds), only the detection with the highest correlation

153 coefficient is kept.

154 With the matched filter analysis, we not only detect almost all events hand-picked by

155 Aiken and Peng [2014], but we also detect many more smaller local earthquakes (Figure S2).

156 Even though some hand-picked events made by Aiken and Peng [2014] are not detected by the

157 matched filter analysis (potentially bad analyst picks), overall the number of events detected

158 around the mainshocks increases (Figure 2a). We compared our detections to the ANSS/ComCat

159 catalog as well as the Enhanced Geothermal Systems (EGS) catalog reported by Lawrence

160 Berkeley National Laboratory and found that on average we improved the catalogs by $\sim 20$ times.

161 In addition, the detection of many more small magnitude events reduces the magnitude of

162 completeness $\left(M_{\mathrm{c}}\right)$ by $\sim 1$ unit (Figure $2 \mathrm{~b}-\mathrm{c}$ ) to -0.1 .
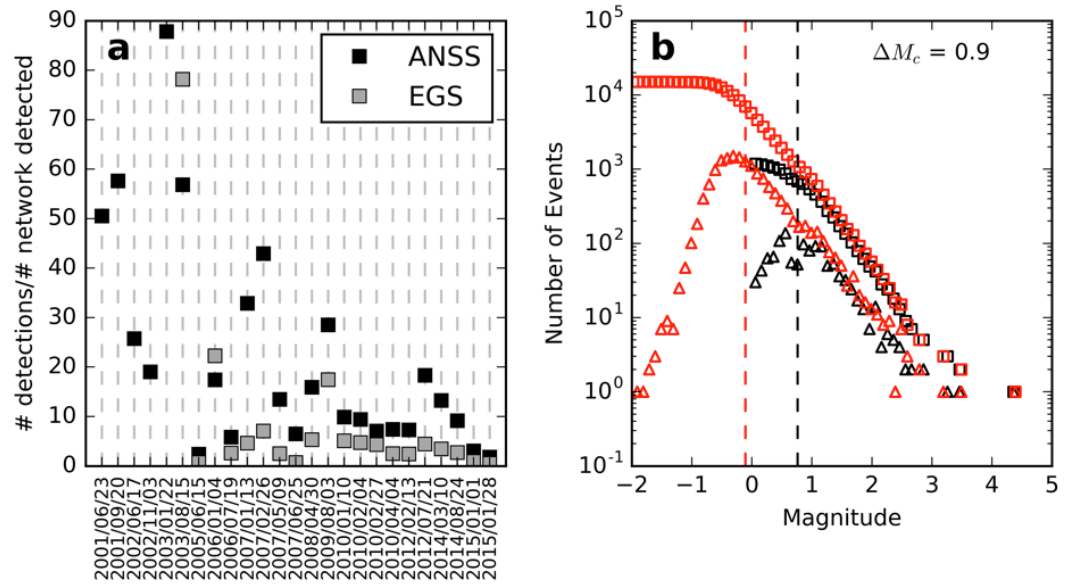
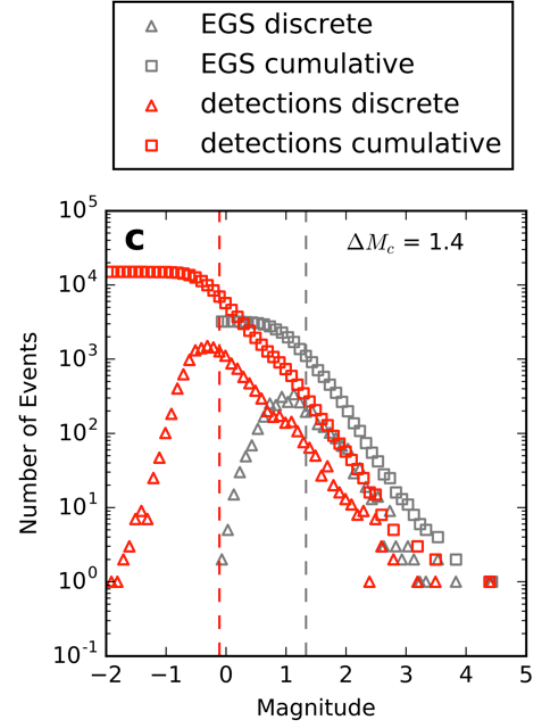
164 Figure 2. Comparison between the combine ANSS and EGS catalogs and our detection catalogs. 165 (a) Ratio of number detections made using matched filter to that reported in ANSS and EGS 166 catalogs combined for each mainshock (see Section 2.1 in supplement for catalog combination).

167 (b) Stacked Gutenberg-Richter distributions for detections made using matched filter and ANSS 168 catalog. Black dashed line marks magnitude of completeness for ANSS $\left(M_{c}=0.8\right)$ and red dashed line marks magnitude of completeness for stacked detection catalogs $\left(M_{c}=-0.1\right)$. (c) Same as (b) but for EGS catalogs. There is a noticeable difference between the magnitudes in the EGS and detection catalogs. This is because the magnitudes of the template events have $M_{d}$ magnitude while EGS reports $M_{L}$ magnitudes. Overall, the magnitude of completeness is improved by $\sim 1$ unit.

\subsection{Focal mechanisms}

177 and take-off angles downloaded from the NCEDC and the program HASH [Hardebeck and

178 Shearer, 2002]. We retained all mechanisms with quality A-C based on Hardebeck and

179 Shearer's [2002] criteria, as well as those having $\geq 10$ polarity observations and a mechanism

180 misfit of $<0.2$ of the total polarities. We assign the focal mechanism of each newly-detected

181 event to be the same as the template event it best matches, under the assumption that nearby

182 events with similar waveforms are likely to have similar mechanisms. If a good-quality

183 mechanism is not available for the best-fitting template, we use the next best fitting template

184 with a mechanism. The focal mechanisms for the detections are approximately one-half strike-

185 slip, one-third normal faulting, and the remaining one-sixth are distributed across a range of

186 reverse and oblique orientations. The average of the strike-slip mechanisms is (strike $=166^{\circ}$,

$187 \operatorname{dip}=84^{\circ}$, rake $=175^{\circ}$, and the average of the normal mechanisms is $\left(\right.$ strike $=19^{\circ}$, dip $=45^{\circ}$, rake $=-$

$1888^{\circ}$ ). These focal mechanisms are consistent with a NNE orientation of maximum horizontal

189 stress, resulting in a normal and strike-slip faulting regime [Boyle and Zoback, 2014]. There may

190 be missing events that have waveforms that are too dissimilar from any of the templates to meet

191 the detection criteria, implying dissimilar focal mechanisms, and these mechanisms would be 
192 unrepresented in the focal mechanism catalog. However, because the template matching

193 detection method used in this study detects almost all of the events that Aiken and Peng [2014]

194 identified by visual inspection using the waveform envelope, there are unlikely to be enough

195 missing events to substantially affect the mechanism distribution. We note that we did not use

196 events that Aiken and Peng [2014] identified by visual inspection in the template matching

197 detection method or in focal mechanism analysis because there is no location information for 198 those events.

200 3. Rate changes around mainshocks

201 With the more complete catalogs formed using the matched filter method (Section 2.2),

202 we can now better assess whether or not triggering occurred at The Geysers following each

203 mainshock by determining if an increase in seismicity rate occurred. To do so, we compute the

204 seismicity rates around the time of each mainshock by applying a sliding window approach on

205 events in the detection catalogs [Ziv et al., 2003; Felzer and Brodsky, 2006], using only events

206 with $M \geq M_{c}=-0.1$ (Section 2.2).

207 In some cases, the seismicity rates are elevated above the background rate in the first 208 several hours following a mainshock. However, other mainshocks indicate no evidence of

209 triggering even after detecting additional small magnitude events using the match filter method

210 (Figure 3). For those mainshocks that have events occurring during the passing seismic waves or

211 up to 30 minutes following a mainshock's $2 \mathrm{~km} \mathrm{~s}^{-1}$ surface wave arrival (to account for a slightly

212 delayed triggering effect), we evaluate the significance of the rate change around the origin time

213 of the triggering mainshocks by computing the $Z$ value [Habermann 1981; Habermann, 1983].

214 The $Z$ value is a quantitative measure of the degree of triggering that compares the background 
215 seismicity rate to the rate following a potential triggering mainshock. We use the $Z$ value because

216 it is a more symmetric version of the $\beta$ value [Marsan and Wyss, 2011]. In general, when $Z \geq$

2171.96 the seismicity rate increase is statistically significant at $95 \%$ confidence level:

218

$$
Z=\frac{N_{a} T_{b}-N_{b} T_{a}}{\sqrt{N_{a} T_{b}^{2}+N_{b} T_{a}^{2}}}
$$

219 where $T_{b}$ and $T_{a}$ are the background and triggering time windows, respectively. In our study, the 220 background time window $\left(T_{b}\right)$ is the time of a mainshock's $P$-wave arrival plus 0.5 day before its 221 origin time. $N_{b}$ and $N_{a}$ are the number of earthquakes in the background and triggering time 222 windows, respectively. 

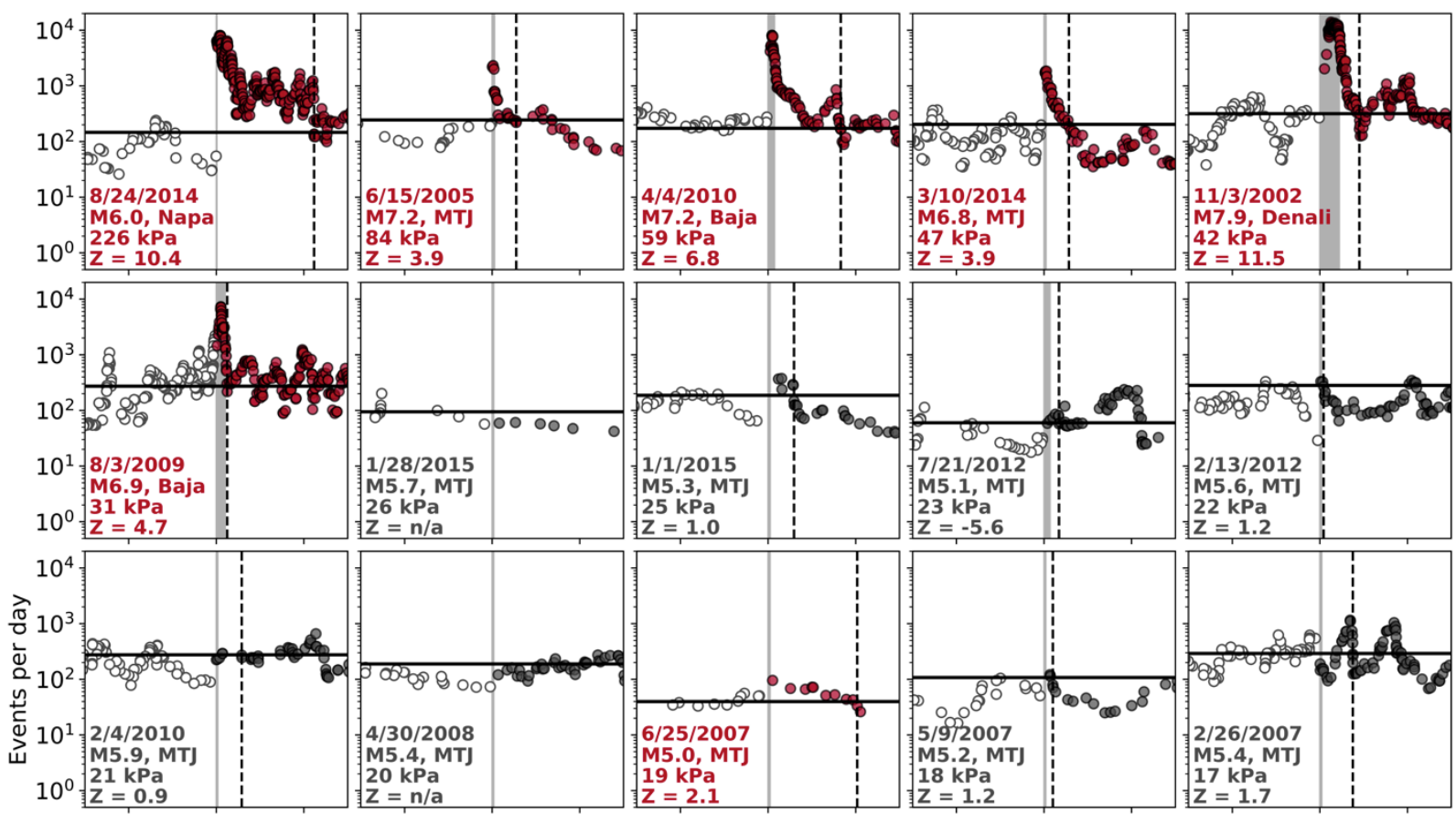
$\mathrm{Z}=-\mathbf{5 . 6}$ $\mathrm{Z}=1.2$
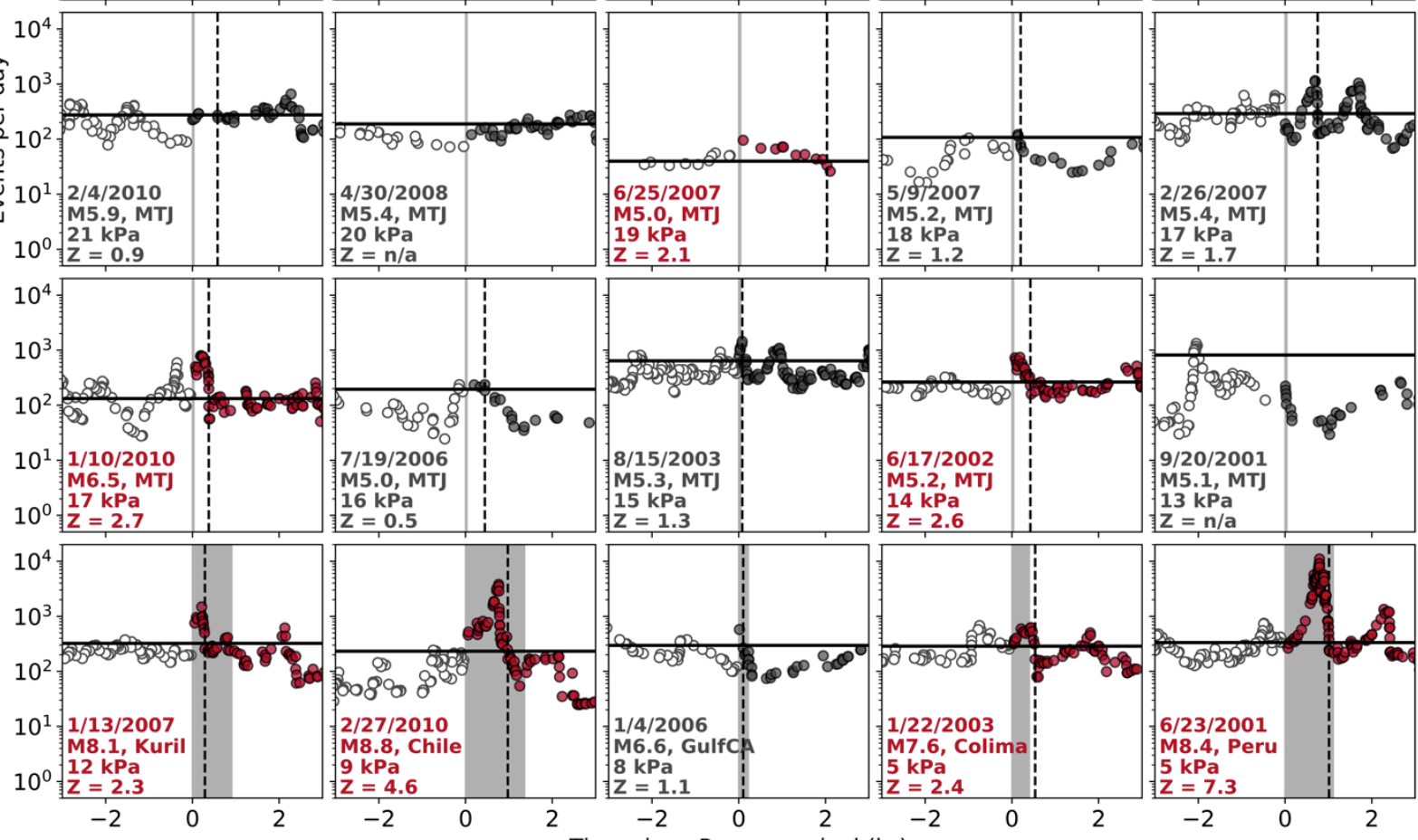

Figure 3. Seismicity rates before (white) and after (red/black) each mainshock. $Z$ values are shown only for potential triggering earthquakes (i.e. distant mainshocks) with seismicity rates above the background rate (solid black line) close to the time of the mainshock (see text for details). Rates shown in red are for mainshocks with statistical significant rate increases $(Z \geq$ 1.96). Gray box $=$ times when a mainshock's seismic waves pass through the region. Dashed line = time at which the seismicity rate following the mainshock first falls below the background rate threshold (solid black line) after the seismic waves began to pass through the region. Max dynamic stress in $\mathrm{kPa}$ computed from measured peak ground velocities as in Aiken and Peng [2014]. Mainshocks are organized top-down, left to right by decreasing dynamic stress. 
235 surface waves imparted stress in the region, i.e. between the $5 \mathrm{~km} \mathrm{~s}^{-1}$ and $2 \mathrm{~km} \mathrm{~s}^{-1}$ wave arrivals.

236 However, triggering can continue long after the surface waves have passed (Figure 3), and a

237 triggering time window set for only during the surface waves of a mainshock will not account for

238 events triggered by a cascading effect [Brodsky, 2006]. Therefore, in this study, we instead

239 determine the length of the triggering time window $\left(T_{a}\right)$ by assessing when the elevated

240 seismicity rate falls below a background rate. We note that in doing so we are maximizing the $Z$

241 value given all possible values of $T_{a}$. To determine $T_{a}$, we first estimate the background rate for

242 each mainshock. Since the background seismicity rate can vary in time, we assume that the

243 background rate is the median rate plus 1 times the median absolute deviation of the rates prior

244 to the $P$-wave arrival of each mainshock. When the seismicity rate following a mainshock falls

245 below the estimated background rate, we assume the triggering window has ended. The start of

246 the triggering window, and thereby the end of the background window, for each mainshock is the

247 arrival of its $P$-wave, as estimated using the iasp91 global velocity model in the TauP program

248 (see Data and Resources). After determining the triggering time window length, we then count

249 the number of events with $M \geq M_{c}=-0.1$ occurring in the triggering time window and the

250 background time window and compute the $Z$ values for mainshocks with events during the

251 passing seismic waves or up to 30 minutes following a mainshock's $2 \mathrm{~km} \mathrm{~s}^{-1}$ surface wave arrival.

252 While most cases of triggering are known in The Geysers [Aiken and Peng, 2014], the

253 matched filter technique increased event detection and helped to delineate previously unclear

254 triggering cases based on the computed $Z$ values (Figure 3). For example, the 2007 Kuril Islands

255 and the 2003 Colima mainshocks were considered to be 'possible' triggering mainshocks by

256 Aiken and Peng [2014] because these mainshocks appeared to instantaneously trigger seismicity 
257 with their passing seismic waves. However, Aiken and Peng [2014] used hand-picked events in 258 their statistical test, which yielded $Z<1$.96. From our matched filter analysis, we found that 259 these mainshocks now have $Z>1.96$, a sign that there was a significant increase in earthquake 260 activity following these mainshocks. The 2006 Gulf of California earthquake was also 261 considered to be a 'possible' triggering source by Aiken and Peng [2014] for the same reasons. 262 However, contrary to previous cases, we determined that the rate change is low and no 263 significant rate change was observed $(Z=1.3)$. Finally, even though our choice of the triggering 264 window length $\left(T_{a}\right)$ maximized the $Z$ value for each mainshock, the $T_{a}$ values did not disagree 265 with easily recognizable triggering or non-triggering cases.

266 The seismicity rates for each mainshock in Figure 3 are ordered top-down left-to-right in

267 order of decreasing dynamic stress $\left(\sigma_{d}\right)$, as computed from each mainshocks' peak ground 268 velocity (PGV) measured at the GDXB station of NC network and by assuming nominal values 269 for shear rigidity $(\gamma, 30 \mathrm{GPa})$ and phase velocity $\left(v_{p h}, 3.5 \mathrm{~km} \mathrm{~s}^{-1}\right)$ for the surface waves, i.e. $\sigma_{d}=\gamma$

$270 * \mathrm{PGV} / v_{p h}[$ Aiken and Peng, 2014]. This expression approximates the maximum dynamic stress

271 change recorded at the surface. Given that there is no site geology or classification for station

272 GDXB (see Data Resources), we assume that the GDXB station is on hard rock. From Figure 3,

273 it is clear that there are potentially two end-members of dynamic triggering - those mainshocks

274 that generate large stress changes and those that generate small stress changes (i.e., mainshocks 275 shown in red). In the next few sections, we explore in detail how these triggering cases are 276 similar to and/or different from each other. 
Geothermal areas like The Geysers are thought to be in a constant state of critical stress

280 due to on-going geothermal energy production and fluid circulation [Hill and Prejean, 2015].

281 For a region that is in a constant state of critical stress, it is reasonable to assume that if

282 triggering does occur that The Geysers will be activated in many areas by the passing seismic

283 waves of a mainshock. This would be especially true if large dynamic stress acts on a critically

284 stressed region since a greater dynamic stress has the potential to activate many more faults, i.e.

285 fault patches that are further from failure. We test this theory by counting the number of

286 triggered events during the triggering time window under the assumption that each triggered

287 event represents a broken fault patch. We count broken fault patches (i.e. number of events

288 triggered) for the 13 triggering mainshocks, excluding mainshocks that do not exhibit

289 statistically significant triggering $(Z<1.96)$ or have no computed $Z$ values (Figure 3 ). We use

290 the same triggering time windows as determined for each mainshock in Section 3.

$291 \quad$ Figure 4a illustrates location of templates detected during the triggering time window for

29213 triggering mainshocks. While most mainshocks triggered small, localized areas, the 2014

293 Napa and 2002 Denali mainshocks triggered most of The Geysers' seismically active area. In

294 comparing the total number of triggered events to the maximum transferred dynamic stress of

295 each mainshock (Figure 4b), we found no correlation. A lack of correlation between transferred

296 dynamic stress and number of events triggered counters the argument of Gomberg and Johnson

297 [2005], who suggested deformation at remote distances causes strain softening and a decrease in

298 resistance to shear, which should ultimately lead to more failure (i.e. more broken fault patches).

299 There are two possible explanations for our observation: 1) if fluid extraction is occurring at the

300 time of triggering, then fault contact area and yield strength may increase or 2) triggering is

301 happening, but asperities (fault patches) only partially slip, and the resulting seismic signal may 
302 be of very small magnitude, i.e. undetectable. However, we do observe a positive correlation

303 between the transferred dynamic stress and the maximum magnitude of triggered events (Figure

304 4c). Mainshocks that transferred the most dynamic stress triggered larger events earlier in the

305 triggering time window (Figure 4c), whereas mainshocks that transferred less dynamic stress

306 triggered slightly smaller magnitude events occurring later in the triggered sequence.

307 Of course, these observations are based the quality of our matched filter detection

308 catalogs. We utilized a detection threshold of 9 times the median absolute deviation (Section 2),

309 which is typical for the matched filter analysis [e.g., Shelly et al., 2007; Peng and Zhao, 2009;

310 Meng et al., 2013]. Meng et al., [2013] found that local templates may falsely match regional

311 earthquakes with correlation coefficients just above the threshold. To eliminate such false

312 detections, one can expand the template library to cover a much larger area, which may increase

313 the computation time by an order. Another way to eliminate false detections is to raise the

314 detection threshold. The higher the detection threshold is, the lower the number of false

315 detections will be. However, a higher threshold would also exclude many small local

316 earthquakes that are buried within noises and significantly reduce the number of detected events.

317 Therefore, we repeat the whole analysis with a moderately higher detection threshold of 12 times

318 the median absolute deviation to evaluate the potential effects of false detections. Because the

319 number of detected earthquakes significantly decreased, the statistical significance for a few

320 triggering cases no longer exist. The number of significant triggering cases reduces from 13 to 7

321 (Table S3). However, with the increased detection threshold, our observations remain the same

322 (Figure S3), that is: 1) no correlation between the number of triggered events and maximum

323 dynamic stress; 2) positive correlation between the dynamic stress and the maximum magnitude 
324 of triggered events; 3 ) the higher the dynamic stress is, the earlier the maximum magnitude event

325 occurs in the sequence.

326
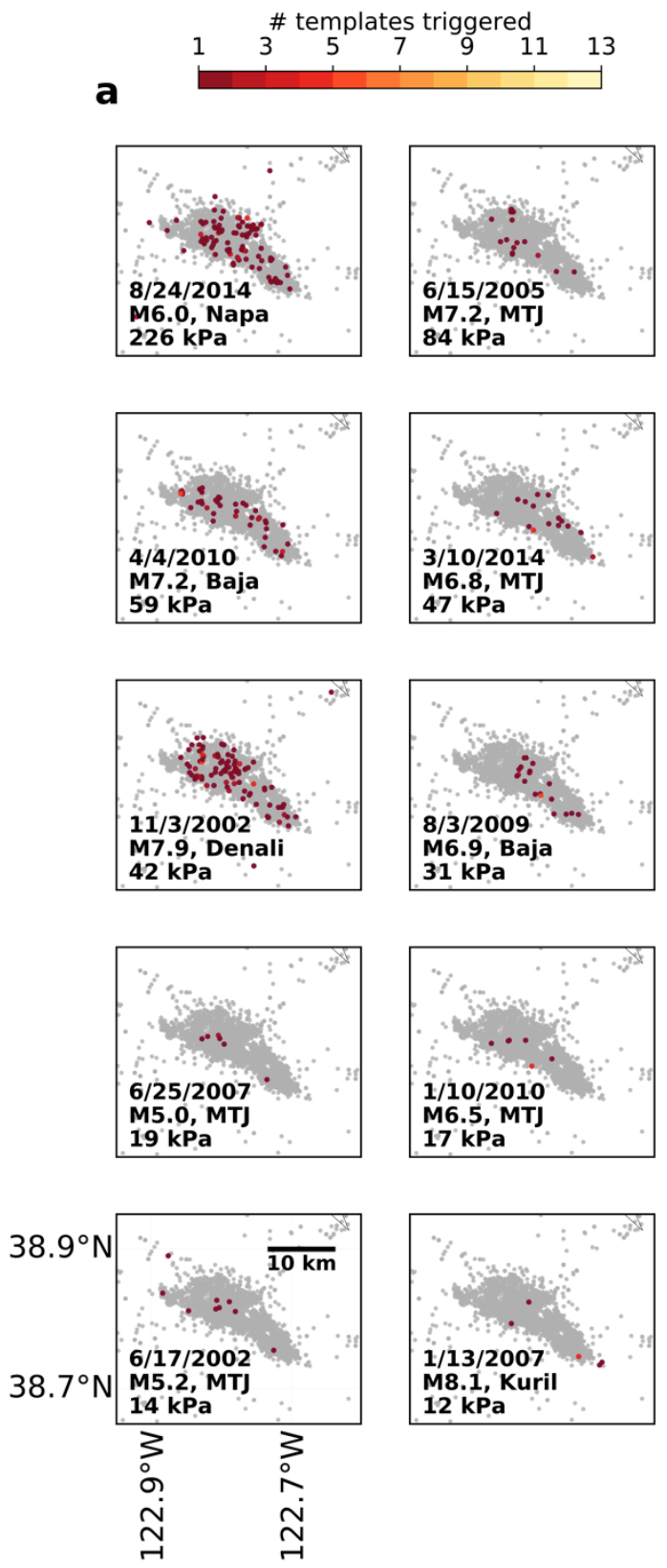
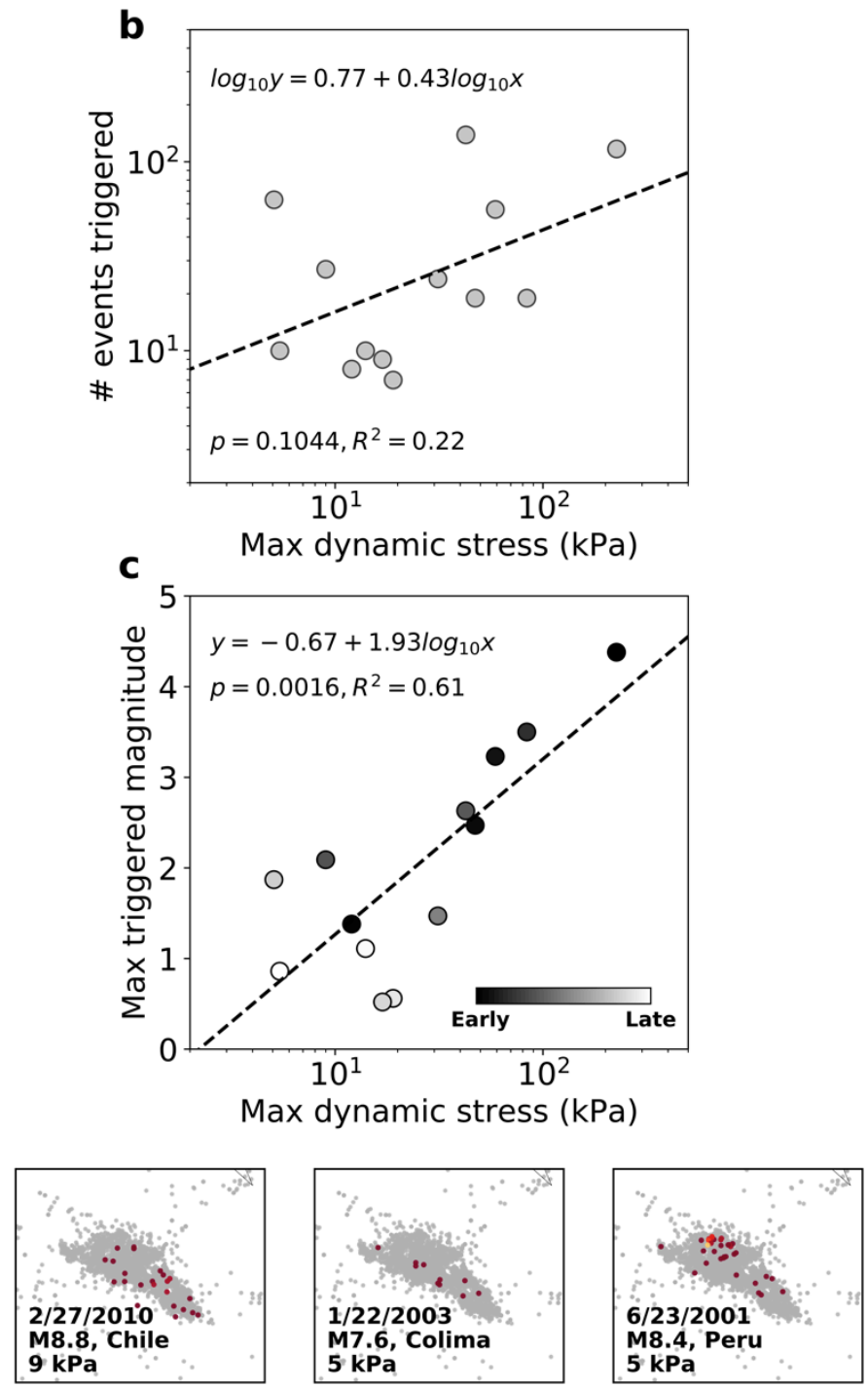

Figure 4. Maximum dynamic stress, number of triggered events, and maximum triggered magnitude during triggering time windows for the 13 triggering mainshocks. (a) Mainshock date, magnitude, location, and maximum dynamic stress are shown. MTJ = Mendocino Triple Junction. All detections made in the region are shown as gray dots. There is no apparent 
333 templates. (b) There is a lack of significant correlation between number of events triggered and 334 maximum dynamic stress transferred. (c) There is a significant positive correlation between 335 maximum magnitude triggered, timing of the largest magnitude in the triggered sequence, and maximum dynamic stress transferred.

\section{5. Orientation dependence of triggering}

We next investigate whether the orientation of the dynamic stresses relative to the focal

340 mechanisms encourages triggering at The Geysers. Previous sections explored the effects of

341 absolute stress amplitude, and here were separately consider the effects of stress orientation. We

342 look for systematic differences in dynamic stress orientations between triggering and non-

343 triggering mainshocks, specifically the normalized dynamic Coulomb stress change resolved on

344 typical Geysers' focal mechanisms (Section 2). The normalized Coulomb stress change measures

345 the stress change on a given fault plane relative to the overall amplitude of the stress change,

346 indicating how well oriented the dynamic stresses are for triggering that particular fault

347 orientation. We define the normalized Coulomb stress change as $\Delta C S / \Delta \tau_{\max }=(\Delta \tau-\mu \Delta \sigma) /\left(\Delta \tau_{\max }\right)$,

348 where $\Delta \sigma$ is the normal stress change on the fault plane, $\Delta \tau$ is the shear stress change in the rake

349 direction, and $\Delta \tau_{\max }$ is the maximum shear stress change on a fault of any orientation (i.e. half the

350 differential stress change). The apparent coefficient of friction, $\mu$, is varied from 0 to 0.8 , and

351 representative results for $\mu=0.4$ are shown. This is a typical value of apparent friction

352 coefficient for Coulomb stress change [e.g., King et al., 1994]

353 We compute the dynamic strain tensor as a function of time for each mainshock in Table

3541 using the Direct Greens Function code of Pollitz [1996], for periods of $\geq 8$ s, low-pass filter at

$35510 \mathrm{~s}, 20 \mathrm{~s}$, or $30 \mathrm{~s}$, and convert to stress by assuming a shear modulus of $30 \mathrm{GPa}$. The stress is

356 computed at $5 \mathrm{~km}$ depth to approximate the shallow depths of the earthquakes. We consider two

357 representative focal mechanisms as determined in Section 2.3, one normal and one strike-slip, 
358 with (strike, dip, rake) of $\left(20^{\circ}, 45^{\circ},-90^{\circ}\right)$ and $\left(170^{\circ}, 90^{\circ}, 180^{\circ}\right)$ and take the largest stress change

359 on either nodal plane of each mechanism. We find the normalized Coulomb stress change at the

360 time of the largest differential stress change, and a weighted average Coulomb stress change over

361 the whole time series to capture more of the high-amplitude stress changes.

362 At longer periods (low-pass at $30 \mathrm{~s}$ ), the normalized Coulomb stress changes tend to be

363 visibly higher on average for the mainshocks with significant triggering $(Z \geq 1.96)$ than for those

364 without significant triggering $(Z<1.96)$ (Figure 5a-d). This holds when we consider the

365 maximum stress changes on representative normal and strike-slip faults and the weighted

366 average stress change on the representative normal and strike-slip faults. A Student's t-test

367 confirms that we can reject the null hypothesis that the results for the events with $Z \geq 1.96$ and $Z$

$368<1.96$ have the same mean with $\geq 95 \%$ confidence, except for the case of the weighted average

369 stress for normal faults. For a low-pass filter at $20 \mathrm{~s}$, the difference is significant only for the

370 strike-slip mechanism, and for a low-pass filter at $10 \mathrm{~s}$, it is only significant for the case of the

371 weighted average for strike-slip faults (Figure 5e). Overall, the results are not highly sensitive to

372 the value of $\mu$ (Figure $5 \mathrm{f}$ ). The stronger correlation with triggering at longer periods is consistent

373 with the results of Hardebeck [2014] for near-field dynamic triggering and suggests that surface

374 waves are responsible for triggering. Moreover, based on The Geysers' dominant faulting

375 orientations and fault orientation of the potentially triggering mainshocks, surface waves tend to

376 be close to or at their greatest triggering potential for triggering mainshocks as opposed to non-

377 triggering mainshocks [Hill, 2012](Figure 6). The results imply that mainshocks are more likely

378 to trigger seismicity at The Geysers if the long-period dynamic stresses are well oriented to load

379 the typical Geysers' focal mechanisms with increased Coulomb stress. 

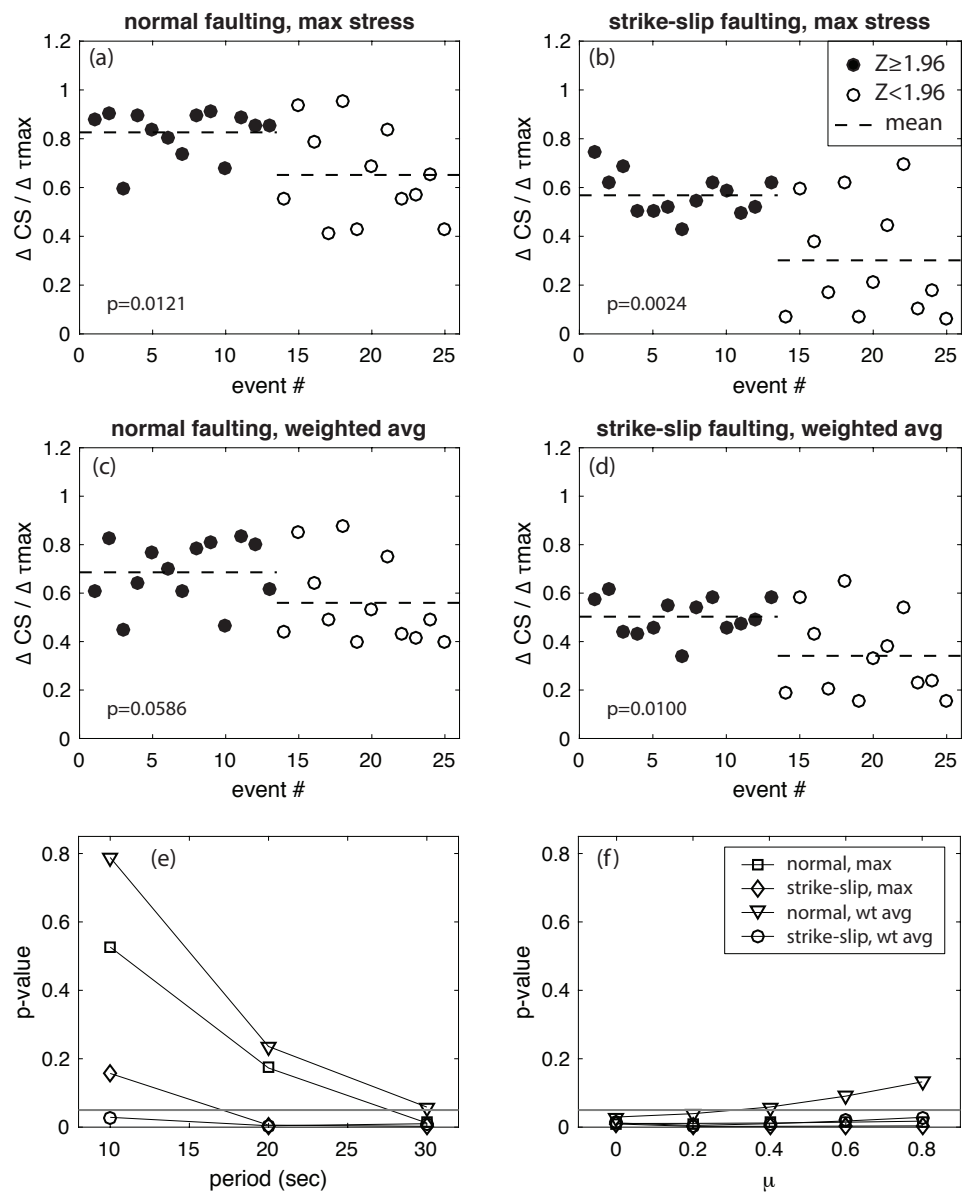

381 Figure 5. (a) Normalized Coulomb stress change at the time of the largest differential stress change, resolved on typical Geysers' normal faulting orientation of strike $=20^{\circ}$, dip $=45^{\circ}$, rake $=-$ $90^{\circ}$, for synthetic stressgrams low-passed at 30s. The triggering (filled circles) and nontriggering (open circles) mainshocks are shown, along with the mean of each (dashed line). The $p$-values are for a Student's t-test of the null hypothesis that the results for the triggering and non-triggering mainshocks have the same mean. (b) Normalized Coulomb stress change at the time of the largest differential stress change, projected on a typical strike-slip orientation of strike $=170^{\circ}$, dip $=90^{\circ}$, rake $=180^{\circ}$. (c) Weighted average normalized Coulomb stress change, projected on the typical normal faulting orientation. (d) Weighted average normalized Coulomb stress change, projected on the typical strike-slip orientation. (e) The $p$-value for the Student's ttest of the null hypothesis that the results for the triggering and non-triggering mainshocks have the same mean, as a function of the period of the low-pass filter applied to the synthetic stressgrams. (f) The $p$-value for the Student's t-test of the null hypothesis, as a function of the assumed apparent coefficient of friction, $\mu$. 

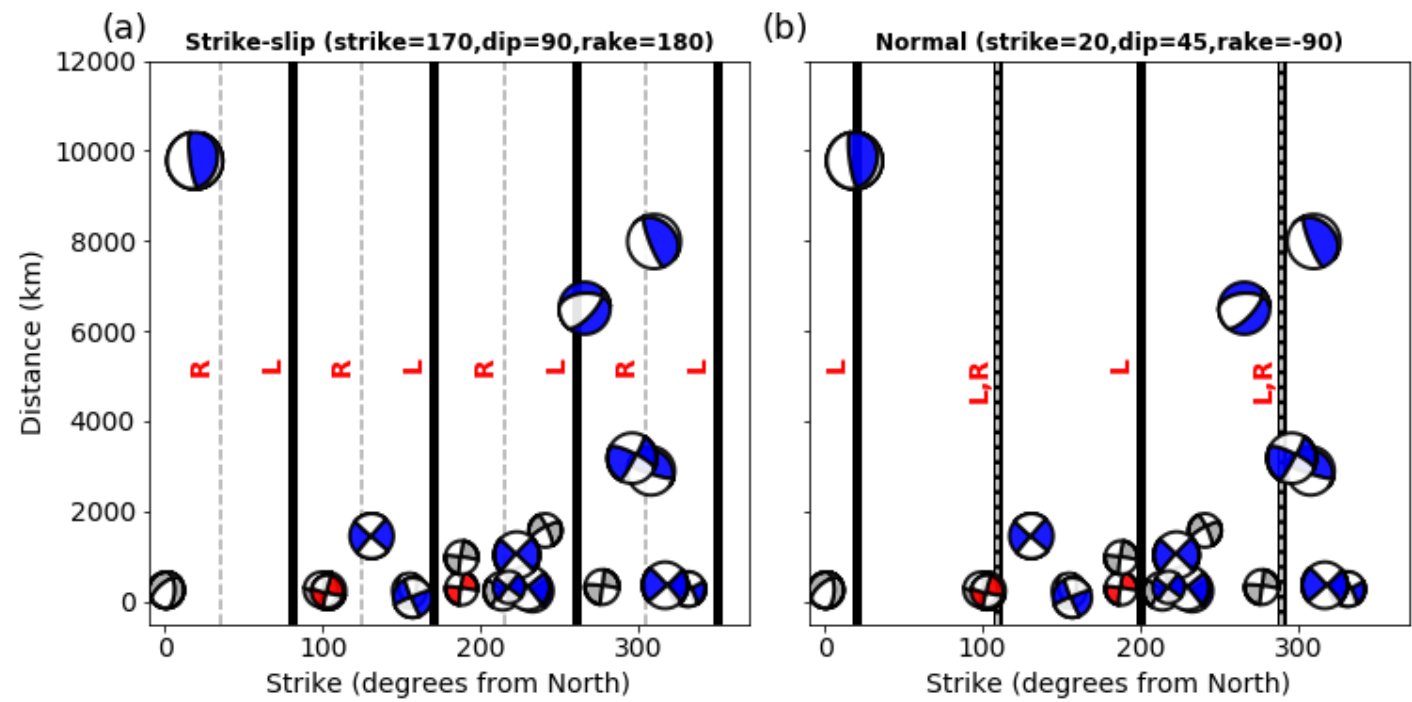

Figure 6. Approximate maximum triggering potential of surface waves from triggering mainshocks (blue) and non-triggering mainshocks (gray/red) on a (a) strike-slip and (b) normal fault in The Geysers. The red focal mechanisms are estimated based on their nearest neighbor (see Figure 1). Solid black lines represent approximate greatest triggering potential for Love waves (L). Dashed gray line represents approximate greatest triggering potential for Rayleigh waves (R). For a normal fault, Love wave maximum triggering potential incidence is similar to a strike-slip fault, but the potential for a Love wave to trigger decreases as fault dip departs from vertical [Hill, 2012].

409 distribution of focal mechanisms than the earthquakes occurring before the mainshock. The

410 aftershock rake directions were better aligned with the dynamic shear stresses resolved on the

411 fault planes, demonstrating that triggering was linked to the orientation of the dynamic stresses.

412 We search for a similar change in focal mechanisms for the triggered events at The Geysers. We

413 characterize the population of focal mechanisms before and after each mainshock as a joint

414 probability distribution function, $P(\theta, \varphi, \lambda)$, of the trend and plunge $(\theta, \varphi)$ of the normal to the

415 nodal plane, and the corresponding rake, $\lambda$. Both nodal planes are included due to the nodal

416 plane ambiguity. We look for significant changes in the focal mechanism distribution by

417 considering $\Delta P(\theta, \varphi, \lambda)=P_{\text {post }}(\theta, \varphi, \lambda)-P_{\text {pre }}(\theta, \varphi, \lambda)$. Some non-zero values of $\Delta P$ will occur simply 
418 due to chance, even if there is no true change in the underlying distribution, due to errors or

419 unrelated fluctuations in the focal mechanism catalog. We characterize the expected distribution

420 of $|\Delta P|$ due to chance by randomly reshuffling the pre- and post-mainshock events.

421 We find that the observed distribution of $|\Delta P|$ generally falls within the middle $95 \%$ of

4221000 realizations of the reshuffled catalogs. Therefore, we consider any changes in the observed

423 mechanism distribution to be due to chance and not reflecting significant changes in the

424 underlying focal mechanism distribution (Figure S4). This holds true for each mainshock

425 individually, as well as for a stack of all mainshocks and a stack of only those mainshocks where

426 the triggering is found to be significant $(Z \geq 1.96)$. To investigate whether a signal may be

427 obscured because the detection threshold is too low to ensure that a detected event and its

428 template have similar focal mechanisms, we try a higher cross-correlation threshold $(0.5)$ and do

429 not find the changes to be significant. Finally, we consider only the first 2 hours of post-

430 mainshock events (there are too few events with mechanisms to limit the analysis to the

431 triggering window), and again do not find the focal mechanism changes to be significant.

432 Comparatively, the plunge of injection-induced earthquakes has been shown to change during

433 times of peak-injection rates but return nearly to before injection plunge after injection rates fall

434 [Martinez-Garzon et al., 2013]. These observations suggest that dynamic stress changes could

435 pressurize fluids in the crust, but that these stress changes are not localized, quasi-static stress

436 changes like that caused by fluid injection. That is to say, the dynamic stress changes from

437 distant mainshocks do not appear to alter the stress field, at least in dynamic triggering time 438 scales.

\section{6. Stress dependence on triggering}




\subsection{Localized stress changes}

442 One factor that could play a role in whether or not triggering occurs is a region's stress

443 state prior to the arrival of a mainshock's seismic waves. Recent laboratory experiments and

444 seismicity studies have shown that the $b$ value of the Gutenberg-Richter equation can possibly be 445 used to approximate the stress state on a fault [Schorlemmer and Wiemer, 2005; Göebel et al.,

446 2013; Tormann et al., 2014]. Therefore, the $b$ value, which describes the size distribution of

447 earthquakes, can possibly act as a 'stressmeter', when the stress state of a region cannot be

448 measured directly $[A k i, 1965]$. In the case of The Geysers, we assess the stress state prior to each

449 mainshock by computing the $b$ value using the maximum likelihood method [Aki, 1965;

450 Marzocchi and Sandri, 2003]:

$$
b=\frac{1}{\ln (10)\left[M_{\text {avg }}-\left(M_{\text {thresh }}-\Delta M / 2\right)\right]}
$$

452 where we set $M_{\text {thresh }}$ to be $M_{c}$ (magnitude of completeness), $M_{\text {avg }}$ is the average magnitude of all

453 events above $M_{\text {thresh }}$ and $\Delta M$ is magnitude binning size (typically 0.1 ). There are many methods

454 for computing the $M_{c}$ of a catalog. In our study, we simply use the maximum curvature method

455 [Wiemer and Wyss, 2000] and add 0.2 units. Adding 0.2 units is considered a more accurate

456 representation of $M_{c}$ when using the maximum curvature method because it provides a similar

457 result to the entire magnitude range method [Mignan and Woessner, 2012].

458 Since earthquake activity varies in space, the $b$ value will also vary in space. To evaluate

459 the $b$ value as a 'stressmeter', we investigate the $b$ value prior to mainshocks in areas that are

460 triggered and not triggered. We create nodes with $0.01^{\circ} \times 0.01^{\circ}$ spacing for The Geysers

461 (longitude $\min / \max : 123^{\circ} \mathrm{W}, 122.6^{\circ} \mathrm{W}$; latitude $\min / \max : 38.6^{\circ} \mathrm{N}, 39^{\circ} \mathrm{N}$ ). For each node, we

462 select earthquakes within a cylinder centered at the node with a radius equal to the greatest

463 distance to the nearest 8 nodes. For example, $0.01^{\circ} \times 0.01^{\circ}$ spacing would have a cylinder radius 
464 of $\left[(1.1 \mathrm{~km})^{2}+(1.1 \mathrm{~km})^{2}\right]^{1 / 2} \approx 1.6 \mathrm{~km}$. We do not regard depth as a factor in our $b$-value 465 calculation because most events occur at depths less than $5 \mathrm{~km}$. At each node, we sample 2,000 466 earthquakes occurring in a cylinder prior to each potential triggering mainshock time to obtain an 467 adequate number of events above the magnitude of completeness $\left(M_{c}\right)$. We compute the $M_{c}$ and 468 then the $b$ value at each node according to equation (3) if there are at least 500 events above the $469 M_{c}$, which guarantees smaller $b$ value error [Nava, 2017]. We note that there are no set time 470 frames for events sampled in the cylinder about a node and that only the last 2000-events 471 occurring before the each potential triggering mainshock time are selected for the calculation.

472 When set time frames were used, in most cases, we found that we did not have enough events to 473 obtain a stable $b$ value for a node.

474 For this calculation, we combine ANSS/ComCat and EGS catalogs from January 2000 to 475 January 2016, removing duplicate events ( $<1$ second apart and $<1 \mathrm{~km}$ apart). For events in The 476 Geysers during our study time period, the ANSS/ComCat catalog reported mostly duration 477 magnitude $\left(M_{d}\right)$ while the EGS catalog reported local magnitudes $\left(M_{L}\right)$. The magnitude 478 differences for duplicate events in our combined ANSS and EGS catalogs is typically $\sim 0.7$ units 479 (Figure S5). Since $b$ value is dependent upon magnitudes sampled, we adjust event magnitudes 480 in the EGS catalog to be comparable to the ANSS/ComCat reported magnitudes by $M_{A N S S}=M_{E G S}$ $481-0.66$ before our $b$ value analysis (for more details see supplementary material). This magnitude 482 adjustment is similar to Hawkins et al. [2017]. We use the combined, magnitude-adjusted 483 catalogs for the $b$ value calculation because our matched filter detections were made up to 12 484 hours prior to the mainshocks, and in most cases, there were not enough detections for an 485 adequate frequency-magnitude distribution. 
We compute $b$ values as described above for each mainshock and for each node,

487 differentiating between triggered and non-triggered nodes. A triggered node is defined as simply

488 a cylinder about the node point that contains at least one event in the triggering time window

489 following a mainshock that exhibits statistical significance, i.e. $Z>1.96$ (Section 3). In addition,

490 we assess the uncertainty in our $b$ value calculations via bootstrapping [Schorlemmer et al., 2003]

491 and with $b$ value error. The $b$ value error, as provided by Shi and Bolt [1982], is:

$$
\sigma_{b}^{S B}=2.3 b^{2} \sqrt{\frac{\sum_{i=1}^{N}\left(M_{i}-M_{a v g}\right)^{2}}{N(N-1)}} .
$$

493 At each node, we construct 100 random samplings with replacement from the true 2,000-event

494 set at that node and compute the mean $b$ value and mean error across the samplings, as described

495 in equations (3) and (4). The $b$ values computed from randomly sampled earthquakes exhibit

496 minor differences from both the true triggered and non-triggered $b$ value distributions,

497 evidencing that our true $b$ values are stable (Figure 7a-b). A Kolmogorov-Smirnov test for

498 similarity between the true triggered and non-triggered node $b$ value distributions yields a $p$ -

499 value $=0.0009$, which suggests that the distributions are different. However, a Student's t-test

500 provides a $p$-value $=1$. Taken together, this illustrates that the means of the true triggered and

501 non-triggered node $b$ value distributions are similar (t-test: $p=1$ ), but their standard deviations

502 are slightly different (Figure 7c). Thus, $b$ value distributions at triggered nodes are not

503 distinguishable from those at non-triggered nodes. In addition, when comparing the number of

504 events triggered in a node to the $b$ value computed at that node, there is no direct evidence that a

505 node with a smaller $b$ value (indication of a region with higher differential stress) is susceptible

506 to having more earthquakes triggered (Figure 7d). These observations hold when node sample

507 spacing is altered (Figure S6, S7), which accounts for some of the detection location uncertainty. 
Given these observations, it seems the $b$ value is not a good indicator for when The

509 Geysers might enter a 'prepared' state for triggering to occur or even where triggering is most

510 likely to occur in the region. There is one possible explanation for $b$ values being

511 indistinguishable between triggered and non-triggered nodes in The Geysers. If the $b$ value is an

512 indicator of differential stress, then similar $b$ values between triggered and non-triggered nodes

513 would suggest that their differential stresses are also likely to be similar. It follows then that for a

514 node to be triggered it probably has a lower mean stress (relative to a non-triggered node),

515 placing it closer to failure [e.g., Beeler, 2000]. That is to say, a triggered and non-triggered node

516 would experience similar dynamic stressing from a distant earthquake, but a node that has lower

517 mean stress (greater pore fluid pressures) would have greater susceptibility to being triggered.

518 We note the $b$ value (slope of the Gutenberg-Richter distribution) is highly dependent

519 upon catalogued events -- detected by a seismic network and/or other methods. While we did not

520 include matched filter detected events in our $b$ value evaluation, the $b$ value observations

521 presented above should not be very different if these detections were included in the analysis.

522 This is because the matched filter method increases the number of small magnitudes events,

523 events that are often missed by seismic networks. Thus, if more small magnitude events were

524 included in the $b$ value evaluation, it would be expected that the $b$ value should either remain the

525 same or increase (Figure 2). Since a high $b$ value is indicative of low differential stress, adding

526 the matched filter detected events to the $b$ value calculation would not significantly alter the

527 conclusion that $b$ values are not a good indicator of The Geysers entering a 'prepared' stress

528 state. 


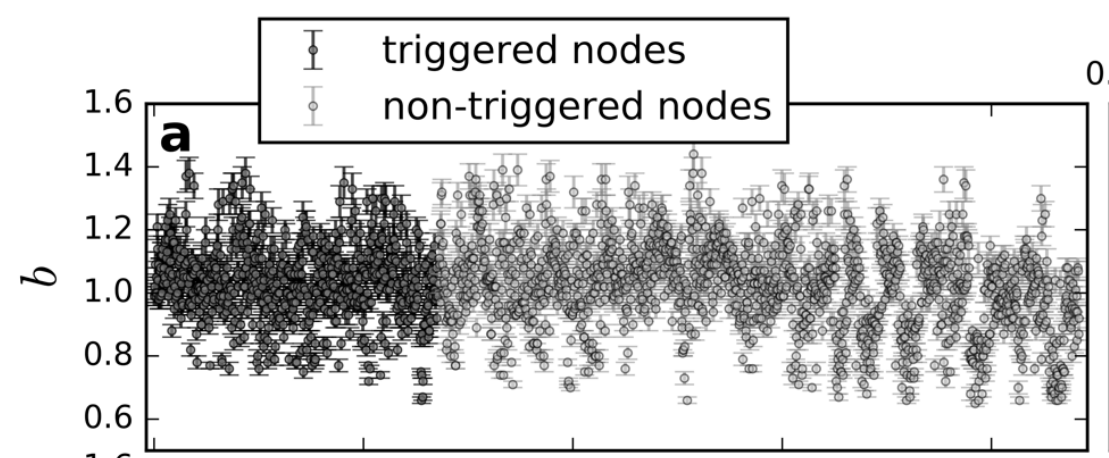

Normalized PDF
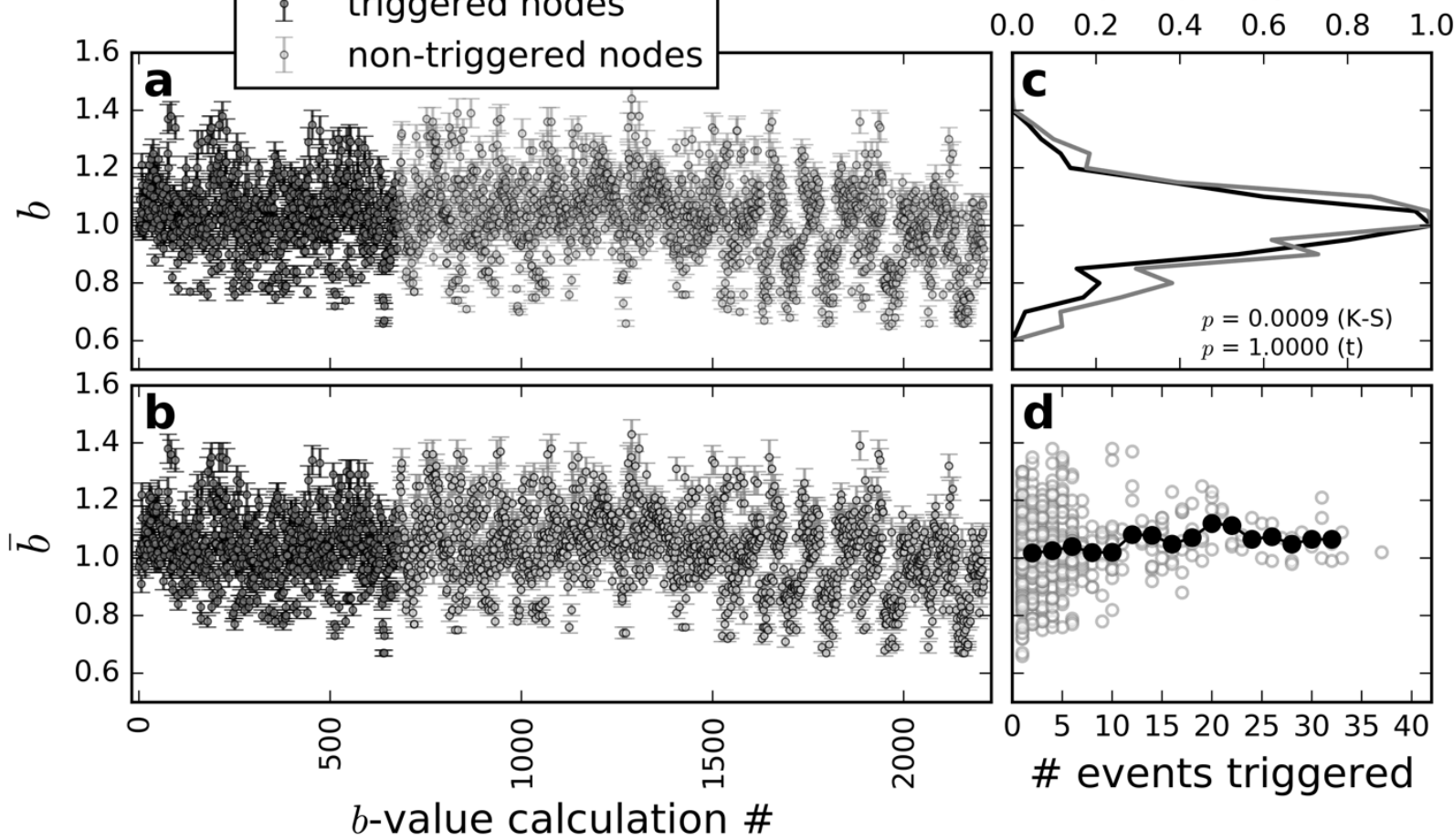

530 Figure 7. (a) Triggered and non-triggered node $b$ value calculations prior to all mainshocks. 531 Error as calculated in equation (4). (b) Same as (a) but for 100 randomly generated earthquake 532 samples at each node. Mean $b$ values and mean error computed from randomly generated 533 catalogs are similar to the true distribution in (a), illustrating $b$ value stability. (c) Normalized 534 probability distribution functions for triggered (black line) and non-triggered (gray line) $b$ value 535 populations in (a), with both having means of 1.02. (d) Open circles: $b$ values at each triggered 536 node and the number of events triggered in that node during the triggering time window. Black 537 circles: rolling mean $b$ value.

\subsection{Tidal stress changes}

Tidal stresses from ocean and solid Earth tides can reach up to as much as $10 \mathrm{kPa}$, the

541 same order of magnitude for dynamic stresses generated by large mainshocks occurring at

542 remote distances (e.g., Figure 4c). Thus, tidal stresses could influence The Geysers response to

543 transient stresses generated by distant mainshocks, if the tidal stresses are significantly large

544 during the same time as the passing seismic waves. Some Programs for Ocean Tide Loading

545 (SPOTL) [Agnew, 1996] can predict tidal strains from gravitational forcing between the Sun,

546 Moon, and Earth as well as loading from changes in ocean tide height. We computed solid-earth 
547 (body) tidal strains around the time of each mainshock using the ertid program within SPOTL

548 and computed ocean tidal strains for the M2, N2, S2, K2, K1, O1, P1, and Q1 frequencies using

549 the global TOPEX/POSEIDON model and a local USA west coast model within the SPOTL

550 program. In all cases, we summed the strains for each frequency component and computed the

551 Hookean stress histories of the tidal forcing in the first 2 hours since each mainshock's $P$ wave

552 arrival in The Geysers, since triggering starts some time during the passing of a mainshock's

553 seismic waves. We assume the shallow crust is a Poisson solid with a shear modulus of $30 \mathrm{GPa}$,

554 where the stresses act anisotropically in The Geysers' fluid-rich environment due to poroelastic

555 effects. We resolved these stresses onto planes parallel to The Geysers two representative

556 faulting styles we observed in this study - strike slip and normal faulting (Section 2). We then

557 used the resolved normal and shear stress changes to compute the Coulomb stress changes ( $\Delta \mathrm{CS})$

558 due to tidal forcing on each fault type, such that

559

$$
\Delta C S=\Delta \tau+\mu\left(\Delta \sigma_{n}-\Delta p\right)
$$

560 where $\Delta \tau$ is shear stress change in the rake direction, $\mu$ is the coefficient of friction, $\Delta \sigma_{n}$ is the

561 normal stress change, and $\Delta p$ is pore pressure change. Here, we assume that $\mu=0.7$ and $\Delta p=-$

$562 \mathrm{~B} \sigma_{k k} / 3$ where $\mathrm{B}$ is the Skempton coefficient $(\mathrm{B}=0.7)$ and $\sigma_{k k}$ is the trace of the stress tensor

563 rotated to the fault planes at each point in time.

$564 \quad$ Figure 8 illustrates the mean Coulomb stress changes ( $\triangle \mathrm{CS})$ computed from the summed

565 body and ocean tidal forces in the first 2 hours following triggering and non-triggering

566 mainshocks. There is no difference in the magnitude of tidal stress changes when triggering

567 occurs and when triggering does not occur for both the normal and strike-slip fault cases. Thus, it

568 seems that tidal stress does not play a role in the timing of The Geysers' susceptibility to

569 triggering. 

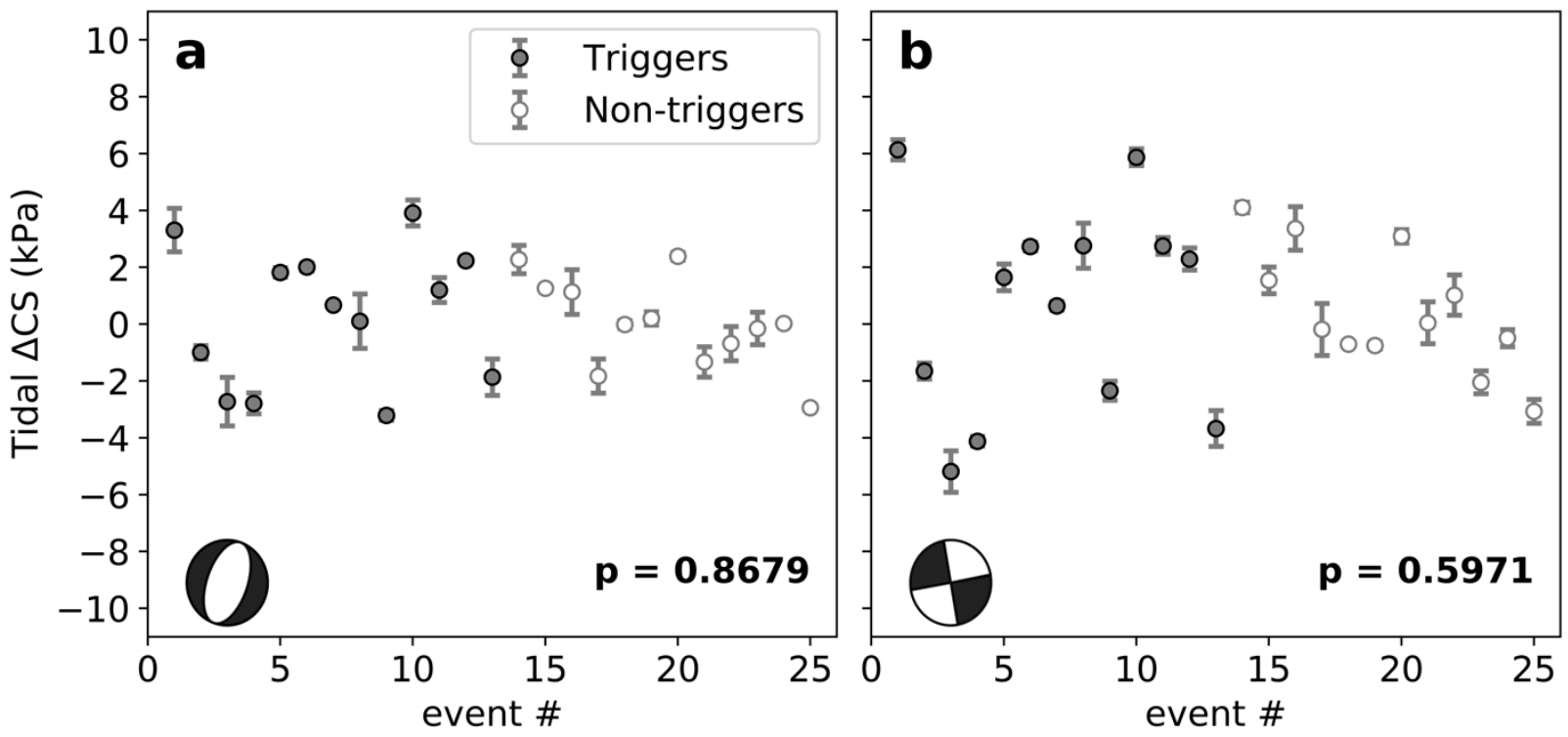

571 Figure 8. Resolved Coulomb stress changes due to solid Earth (body) and ocean tidal forcing on 572 The Geysers representative (a) normal fault and (b) strike-slip fault during the first 2 hours

573 following the $P$ wave arrival of the 25 mainshocks. As shown by the $p$ values from Kolmogorov-

574 Smirnov tests, there is no difference between tidal stresses when triggering occurs $(Z>1.96)$ and 575 when triggering does not occur $(Z<1.96)$ for either fault type. Thus, tidal forcing does not seem to have any effect on Geysers' susceptibility to triggering. Event \# in this figure is the same as in Figure 5a-d.

\section{Discussion}

Dynamic triggering has been identified in non-geothermal regions such as fluid-injection

582 sites in the Central US [van der Elst et al., 2013], but The Geysers' is a unique site for testing the

583 'predictability' of dynamic triggering. Beyond having fluid mass fluctuations, it has been

584 suggested The Geysers has a greater susceptibility to triggering based on it's higher heat flow

585 [Aiken and Peng, 2014] and background seismicity rate [Hill and Prejean, 2015]. However, it's

586 possible that The Geysers' appears to be uniquely more susceptible because of its proximity to

587 repeatable triggering sources coming from the MTJ. In this study, we discovered that there is

588 some repeatability of triggering in The Geysers with mainshocks occurring in the MTJ of a

589 certain size and orientation (Figures 1 and 6). The Geysers may, in the future, be repeatedly 
590 triggered by more distant mainshocks (i.e. teleseisms). However, at teleseismic distances, larger

591 magnitude mainshocks are required for triggering to be observed, and larger magnitude

592 mainshocks are far less frequent than those occurring in the MTJ. Thus, more observation time is

593 needed to test the repeatability of triggering by mainshocks at teleseismic distances.

594 We found that maximum magnitude of triggered events positively correlates with peak

595 dynamic stress changes, and at larger dynamic stress changes ( $>20 \mathrm{kPa})$, the highest magnitude

596 triggered event tends to occur earlier in the triggered sequence (Figure 4c). This suggests that

597 larger dynamic stresses are more likely to encourage mainshock-aftershock type sequences, a

598 phenomenon previously observed in The Geysers [Brodsky, 2006]. On the other hand, smaller

599 peak dynamic stresses tend to trigger smaller magnitude events with the highest magnitude

600 triggered event occurring much later in the sequence, suggesting more swarm-like behavior.

601 Thus, we may be able to forecast the largest magnitude of the triggered sequence, and perhaps

602 even how the triggering episode will evolve in time.

603 We considered the possibility that triggering might occur when The Geysers is in a high

604 differential stress state, a preparatory stage for the release of stress in a triggering episode. While

605 it has been shown (in retrospect) that the $b$ value of the Gutenberg-Richter magnitude-frequency

606 distribution could map high differential stress and an impending earthquake rupture area [e.g.,

607 Schorlemmer and Wiemer, 2005], we found no significant difference between $b$ values in

608 triggered areas and non-triggered areas (Figure 7). Small magnitude earthquakes, like those in

609 The Geysers' triggering episodes, occur regularly in The Geysers due to the on-going geothermal

610 energy production, and thus there may not be a significant amount of time for stress build up that

611 could be visible with a spatial $b$-value analysis. Moreover, since we observed similar $b$ values in

612 triggered and non-triggered nodes and The Geysers has mostly small magnitude $(M<4)$ events, 
613 we presume that highly variable fluid mass fluctuations for energy production may lower

614 recurrence times by creating a highly fractured network of many nucleation points. This might

615 break standard ideas about the distribution of earthquake behavior in time, such as the slope of

616 the Gutenberg-Richter distribution ( $b$ value) prior to triggering. Hence, it remains unclear if

617 small magnitude events can be used to understand local stress state.

618 It has been shown that tidal stresses from solid Earth tides and ocean loading can 619 influence slow earthquake (a.k.a. tremor) activity [Thomas et al., 2009; Houston, 2015], but we

620 found no evidence that tidal stresses have any influence on when triggering happens in The

621 Geysers (Figure 8). This counters recent observations that tidal forcing can influence earthquake

622 activity in non-geothermal regions, a relationship that is highly dependent upon the magnitude of

623 the tidal stress [Bucholc and Steacy, 2016]. The tidal stress changes we observed were at most

$624+/-6 \mathrm{kPa}$ during the triggering time window, the same order of magnitude but still less than

625 current triggering thresholds for geothermal areas of California [Aiken and Peng, 2014]. Yet, we

626 observed no clear distinction between tidal stress changes during triggering and non-triggering

627 mainshocks. Therefore, it remains unclear what role, if any, tidal stresses and local stresses may

628 play in the triggering process.

629

\section{8. Conclusions}

631 At present, seismicity induced by geothermal energy production at The Geysers is not 632 generally considered to pose a significant seismic hazard [e.g., Majer et al., 2007]. However, 633 based on this study, it appears that larger dynamic stress changes from distant mainshocks trigger

634 larger events. Therefore, it is vital to understand when, where, and how triggering will occur for 635 the safety of on-going energy operations at The Geysers, especially since moderate sized 
636 earthquakes occurring in the Mendocino Triple Junction repeatedly trigger the region and occur

637 more frequently than larger, more distant earthquakes. But how 'predictable' is dynamic

638 triggering of earthquakes at The Geysers? With the few cases we investigated in this study, it is

639 clear that at least the timing and location of triggering is not well understood.

640 The most difficult challenge in understanding the 'predictability' of dynamically

641 triggered earthquakes is determining where the weak points are (when and where triggering is

642 most likely to happen) and what controls those weaknesses. One likely factor that we did not

643 investigate in this study is the role of fluid mass fluctuations. Brodsky and Lajoie [2013] showed

644 that earthquake activity in Salton Sea geothermal field, at least, is closely tied to the total fluid

645 volume. However, it was beyond the scope of this work to investigate whether or not fluid

646 injection/extraction volumes in The Geysers heightens susceptibility to dynamic triggering.

647 Since triggered earthquakes sometimes occur in isolated areas (Figure 4a), it may even be

648 worthwhile to analyze fluid-injection volumes at individual wells and their relationships with

649 earthquake activity [e.g., Majer and Peterson, 2007; Langenbruch and Zoback, 2016]. Such

650 investigations would add some clarity to The Geysers' stress state around the times triggering

651 does and does not happen and where triggering might happen in the future.

\section{Data and Resources}

654 Waveform data, metadata, or data products for this study were accessed through the Northern 655 California Earthquake Data Center (NCEDC), doi:10.7932/NCEDC. The ANSS catalog is a 656 comprehensive catalog (a.k.a. ComCat) is accessible at http://www.ncedc.org/anss/catalog657 search.html (last accessed July 27, 2017). The EGS catalog is a catalog developed by Lawrence 658 Berkeley National Laboratory and is accessible at http://www.ncedc.org/egs/catalog-search.html 659 (last accessed July 27, 2017). Phase arrival times were computed using the TauP program, freely 660 available at http://www.seis.sc.edu/TauP/. Focal mechanisms of The Geysers' earthquakes were 661 computed using the HASH program, freely available at

662 https://earthquake.usgs.gov/research/software/\#HASH. Focal mechanisms of potentially 
663 triggering mainshocks were taken from the openly available Harvard CMT catalog

664 (http://www.globalcmt.org/CMTsearch.html, last accessed January 16, 2018).

665 We assessed site geology for the GDXB station from the Center for Engineering Strong Motion

666 Data (http://www.strongmotioncenter.org/cgi-

667 bin/CESMD/stationhtml.pl?stationID=NCGDXB\&network=NCSN, last accessed November

668 17, 2017). Figures 1, 2, 4, and 5 were made using Python 3.3, an open source programming

669 language.

670

\section{Acknowledgements}

672 We thank Justin Rubinstein and Andrea Llenos for comments that improved an earlier draft of 673 our manuscript. We also thank two anonymous reviewers for their time and helpful feedback that 674 greatly improved the quality of our manuscript. UTIG contribution \#3142.

675

\section{References}

677 Agnew, D. C. (1996), SPOTL: Some programs for ocean-tide loading, SIO Ref. Ser. 96-8, 35 pp., Scripps Institution of Oceanography, La Jolla, CA.

680

681

682

683

684

685

686

687

688

689

690

691

692

693

694

695

696

697

698

699

700

701

702

703

Aki, K. (1965), Maximum likelihood estimate of $\mathrm{b}$ in the formula $\log \mathrm{N}=\mathrm{a}-\mathrm{bM}$ and its confidence limits, Bull. Earthq. Res. Inst., 43, 237-239.

Aiken, C. and Z. Peng (2014), Dynamic triggering of microearthquakes in three geothermal regions of California, J. Geophys. Res., 119, 6992-7009, doi: 10.1002/2014JB011218.

Aiken, C., Z. Peng, and K. Chao (2013), Tremors along the Queen Charlotte Margin triggered by large teleseismic earthquakes, Geophys. Res. Lett., 40, doi:10.1002/grl.50220.

Brodsky, E. E. (2006), Long-range triggered earthquakes that continue after the wave train passes, Geophys. Res. Lett., 33, L15313, doi:10.1029/2006GL026605.

Brodsky, E. E. and L. J. Lajoie (2013), Anthropogenic seismicity rates and operational parameters at the Salton Sea Geothermal Field, Science, 341, 543-546, doi: $10.1126 /$ science. 1239213 .

Brodsky, E. E. and N. J. van der Elst (2014), The uses of dynamic earthquake triggering, Annu. Rev. Earth Pl. Sc., 42, 317-339, doi: 10.1146/annualrev-earth-060313-054648.

Boyle, K., and M. Zoback (2014), The Stress State of the Northwest Geysers, California Geothermal Field, and Implications for Fault-Controlled Fluid Flow, Bull. Seismol. Soc. Am., doi: 10.1785/0120130284.

Bucholc, M. and S. Steacy (2016), Tidal stress triggering of earthquakes in Southern California, 704 Geophys. J. Int., 205, no. 2, 681-693, doi: 10.1093/gji/ggw045. 
Dieterich, J. (1994), A constitutive law for rate of earthquake production and its application to earthquake clustering. J. Geophys. Res., 99, B2, 2601-2618, doi:10.1029/93JB02581.

Felzer, K. and E. E. Brodsky (2006), Decay of aftershock density with distance indicates triggering by dynamic stress, Nature, 441, 735-738, doi: 10.1038/nature04799.

Goebel, T. H. W., D. Schorlemmer, T. W. Becker, G. Dresen, C. G. Sammis (2013), Acoustic emissions document stress changes over many seismic cycles in analog experiments, Geophys. Res. Lett., 40, no. 10, 2049-2054, doi:10.1029/2013GL050507.

Gomberg, J. (2010), Lessons from (triggered) tremor, J. Geophy. Res., 115, B10302, doi: 10.1029/2009JB007011.

Gomberg, J. and Johnson, P. A. (2005), Dynamic triggering of earthquakes, Nature 473, 830, doi: $10.1038 / 437830$ a.

Gonzalez-Huizar, H. and A. A. Velasco (2011), Dynamic triggering: Stress modeling and a case study, J. Geophys. Res., 116, B02304, doi: 10.1029/2009JB007000.

Habermann, R. E. (1981), Precursory seismicity patterns: Stalking the mature seismic gap, in Earthquake Prediction - An international review, ed. D. W. Simpson and P. G. Richards, pp. 29-42, American Geophysical Union.

Habermann, R. E. (1983), Teleseismic detection in the Aleutian Island Arc, J. Geophys. Res., $88,5056-5064$.

Hardebeck, J. L. (2014), The impact of static stress change, dynamic stress change, and the background stress on aftershock focal mechanisms, J. Geophys. Res., 119, no. 11, 82398266, doi: 10.1002/2014JB011533.

Hardebeck, J. L. and P. M. Shearer (2002), A new method for determining first-motion focal mechanisms, B. Seismol. Soc. Am., 92, no. 6, 2264-2276.

Hawkins, A., D. L. Turcotte, M. B. Yikilmaz, L. H. Kellog, and J. B. Bundle (2017), Statistical studies of induced and triggered seismicity at The Geysers, California, Pure Appl. Geophys., 174, no. 6, 2443-2456, doi: 10.1007/s00024-017-1569-z.

Hill, D. P. (2012), Surface wave potential for triggering tectonic (non-volcanic) tremor -Corrected, B. Seismol. Soc. Am., 102, no. 6, 2313-2336, doi:10.1785/0120120085.

Hill, D. P. (2015), On the sensitivity of transtensional versus transpressional tectonic regimes to remote dynamic triggering by Coulomb failure, B. Seismol. Soc. Am., 105, no. 3, doi:10.1785/0120140292.

Hill, D. P., et al. (1993), Seismicity remotely triggered by the magnitude 7.3 Landers, California, 
earthquake, Science, 260(5114), 1617-1623.

Hill, D. P. and S. G. Prejean (2015), Dynamic Triggering, in Treatise on Geophysics $2^{\text {nd }}$ edition

Houston, H. (2015), Low friction and fault weakening revealed by rising sensitivity of tremor to tidal stress, Nat. Geosci., 8, 409-415, doi: 10.1038/ngeo2419.

King, G. C. P., R. S. Stein, and J. Lin (1994), Static stress changes and the triggering of earthquakes, B. Seismol. Soc. Am., 84, no. 3, 935-953.

Langenbruch, C. and M. D. Zoback (2016), How will induced seismicity in Oklahoma respond to decreased saltwater injection rates?, Science Advances, 2, no. 11, e1601542, doi: 10.1126/sciadv.1601542.

Majer, E. L. and J. E. Peterson (2007), The impact of injection on seismicity at The Geysers, California Geothermal Field, Int. J. Rock Mech. Min., 44, no. 8, 1079-1090, doi: 10.1016/j.jirmms.2007.07.023.

Marsan, D. and M. Wyss (2011), Seismicity rate changes, Community Online Resource for Statistical Seismicity Analysis, doi: 10.5078/corssa-25837590. Available at http://www.corssa.org.

Martínez-Garzon, P., M. Bohnhoff, G. Kwiatek, and G. Dresen (2013), Stress tensor changes related to fluid injection at The Geysers geothermal field, California, Geophys. Res. Lett., 40, no. 11, 2596-2601, doi: 10.1002/grl.50438.

Marzocchi, W. and L. Sandri (2003), A review and new insights on the estimation of the $b$-value and its uncertainty, Ann. Geophys. Italy, 46, no. 6, $1271-1282$.

Meng, X., Z. Peng, and J. Hardebeck (2013), Seismicity around Parkfield correlates with static shear stress changes following the 2003 Mw6.5 San Simeon earthquake, J. Geophys. Res., 118, no. 7, 3576-3591, doi: 10.1002/jgrb.50271.

Mignan, A., J. Woessner (2012), Estimating the magnitude of completeness for earthquake catalogs, Community Online Resource for Statistical Seismicity Analysis, doi:10.5078/corssa-00180805. Available at http://www.corssa.org.

Nava, F. A., V. H. Márquez-Ramírez, F. R. Zúñiga, L. Ávila-Barrientos, C. B. Quinteros (2017), Gutenberg-Richter $b$-value maximum likelihood estimation and sample size, J. Seismol., 21, no. 1, 127-135, doi: 10.1007/s10950-016-9589-1.

Peng, Z., J. Walter, R. Aster, A. Nyblade, D. Wiens, and S. Anandakrishnan (2014), Antartic icequakes triggered by the 2010 Maule earthquake in Chile, Nat. Geosci., 7, 677-681, doi: 10.1038/NGEO2212. 
Peng, Z., and P. Zhao (2009), Migration of early aftershocks following the 2004 Parkfield earthquake, Nat. Geosci., 2(12), 877-881.

800

801

802

803

804

805

806

Prejean, S. G., D. P. Hill, E. E. Brodsky, S. E. Hough, M. J. S. Johnston, S. D. Malone, D. H. Oppenheimer, A. M. Pitt, and K. B. Richards-Dinger (2004), Remotely triggered seismicity on the United States west coast following the Mw7.9 Denali Fault earthquake, B. Seismol. Soc. Am., 94, No. 6B, S348-S359, doi: 10.1785/0120040610.

Pollitz, F. F. (1996), Coseismic deformation from earthquake faulting on a layered spherical Earth, Geophys. J. Int., 125, no. 1, 1-14, doi: 10.1111/j.1365-246X.1996.tb06530.x.

Schaff, D. P. and P. G. Richards (2014), Improvements in magnitude precision, using the statistics of relative amplitudes measured by cross correlation, Geophys. J. Int., 197, no. 1, 335-350, doi: $10.1093 /$ gji/ggt433.

Schorlemmer, D., G. Neri, S. Wiemer, and A. Mostaccio (2003), Stability and significance tests for $b$-value anomalies: Example from the Tyrrhenian Sea, Geophys. Res. Lett., 30, no. 16, doi: 10.1029/2003GL017335.

Schorlemmer, D. and S. Wiemer (2005), Microseismicity data forecast rupture area, Nature, 434, 1086.

Shelly, D., G. Beroza, and S. Ide (2007), Non-volcanic tremor and low-frequency earthquake swarms, Nature, 446(7133), 305-307.

Shi, Y. and B. A. Bolt (1982), The standard error of the magnitude-frequency $b$ value, $B$. Seismol. Soc. Am., 72, no. 5, 1677-1687.

Tormann, T., S. Wiemer, and A. Mignan (2014), Systematic survey of high-resolution $b$ value imaging along Californian faults: Inference on asperities, J. Geophys. Res., 119, no. 3, 20292054, doi: 10.1002/2013JB010867.

Thomas, A., R. M. Nadeau, and R. Bürgmann (2009), Tremor-tide correlations and nearlithostatic pore pressure on the deep San Andreas fault, Nature, 462, 1048-1051, doi: 10.1038 /nature 08654 .

van der Elst, N. J., H. M. Savage, K. M. Keranen, and G. A. Abers (2013), Enhanced remote earthquake triggering at fluid-injection sites in the Midwestern United States, Science, 341, 164-167, doi: 10.1126/science.1238948.

Wiemer, S., and M. Wyss (2000). Minimum magnitude of complete reporting in earthquake catalogs: examples from Alaska, the Western United States, and Japan, Bull. Seismol. Soc. Am., 90, $859-869$. 
842 Ziv, A., A. M. Rubin, and D. Kilb (2003), Spatiotemporal analyses of earthquake productivity 843 and size distributation: Observations and simulations, B. Seismol. Soc. Am., 93, no. 5, 2069$844 \quad 2081$, doi: $10.1785 / 0120020117$. 


\title{
Electronic Supplement for
}

\section{Testing for the 'predictability' of dynamically triggered earthquakes in The Geysers geothermal field}

\author{
Authored by
}

Chastity Aiken, Xiaofeng Meng, and Jeanne Hardebeck

\section{Introduction}

This supplementary text contains the supplemental text, 9 supplementary figures and 2 supplementary tables.

\section{Supplemental Text}

\subsection{Combining ANSS/ComCat and EGS catalogs}

As seen in Figure 2 of the main text, the EGS earthquake catalog (see Data and Resources) is more complete than the ANSS/ComCat catalog. However, it only reports from 2003 to present. Since our potential triggering earthquake selection time period begins in 2001, we combine the ANSS/ComCat and EGS catalogs.

The EGS catalog reports local magnitudes $\left(M_{L}\right)$, while ANSS/ComCat reports a variety of magnitudes -- mostly $M_{d}$ (duration magnitude) -- but also a few $M_{L}$ and $\mathrm{M}_{\mathrm{x}}$ ('x' possibly meaning average?) for The Geysers. Events with very similar origin times and locations appear in both the ANSS/ComCat and EGS catalogs but with different magnitudes and magnitude types. Since the Gutenberg-Richter $b$ value (see Section 6.1 of main text) is dependent upon magnitude, it is important that similar magnitude types are used in the analysis.

To convert EGS $M_{L}$ reported magnitudes to $M_{d}$ magnitudes, we first determine events that are commonly reported in both the ANSS/ComCat and EGS catalogs. We define common reported events between the catalogs as having an origin time $<1$ second and a separation distance $<1 \mathrm{~km}$. We keep only ANSS/ComCat events that have magnitude type $M_{d}$ and EGS events with magnitude $M_{L}$. We plot ANSS reported magnitude $\left(M_{d}\right)$ vs. EGS reported magnitude $\left(M_{L}\right)$ and perform a linear regression on the data (Figure S5). We find that to convert EGS reported magnitude $\left(M_{L}\right)$ to $M_{d}$ we must use the following formula:

$$
M_{A N S S}=M_{E G S}-0.66
$$

which is similar to the results of Hawkins et al. [2017].

\section{Supplemental Figures}




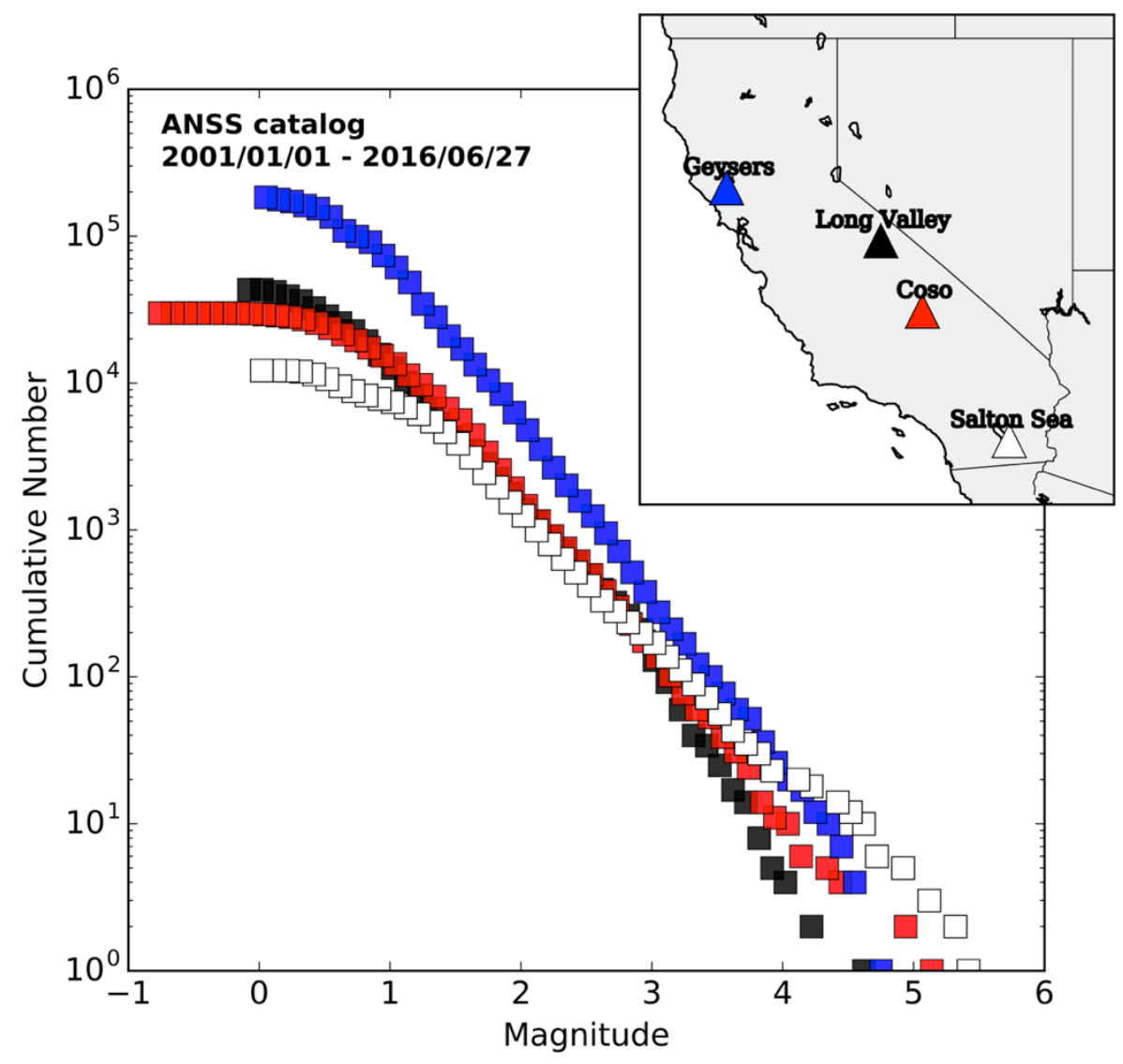

Figure S1. Over the last 15 years, The Geysers geothermal field has been the most seismically active geothermal region in California - more so than Long Valley Caldera, Coso geothermal field, and Salton Sea geothermal field combined, even when considering only events with $M \geq 2$. Geysers had 6305 earthquakes with $M \geq 2$, while Long Valley Caldera, Coso Geothermal Field, and Salton Sea Geothermal Field had 1541, 1924, and 1762 events, respectively. Only shallow $(<10 \mathrm{~km})$ events within a $0.4^{\circ} \times 0.4^{\circ}$ area (colored squares) are shown as reported by the Advanced National Seismic System. The Geysers geothermal field (longitude $\mathrm{min} / \mathrm{max}: 123^{\circ} \mathrm{W}$, $122.6^{\circ} \mathrm{W}$; latitude $\min / \max : 38.6^{\circ} \mathrm{N}, 39^{\circ} \mathrm{N}$ ); Long Valley (longitude $\min / \mathrm{max}: 119.1^{\circ} \mathrm{W}$, $118.7^{\circ} \mathrm{W}$; latitude $\min / \max : 37.45^{\circ} \mathrm{N}, 37.85^{\circ} \mathrm{N}$ ); Coso geothermal field (longitude $\min / \max$ : $118.05^{\circ} \mathrm{W}, 117.65^{\circ} \mathrm{W}$; latitude $\min / \max$ : $\left.35.9^{\circ} \mathrm{N}, 36.3^{\circ} \mathrm{N}\right)$; Salton Sea geothermal field (longitude $\min / \max : 115.86^{\circ} \mathrm{W}, 115.46^{\circ} \mathrm{W}$; latitude $\min / \max : 33^{\circ} \mathrm{N}, 33.4^{\circ} \mathrm{N}$ ) 


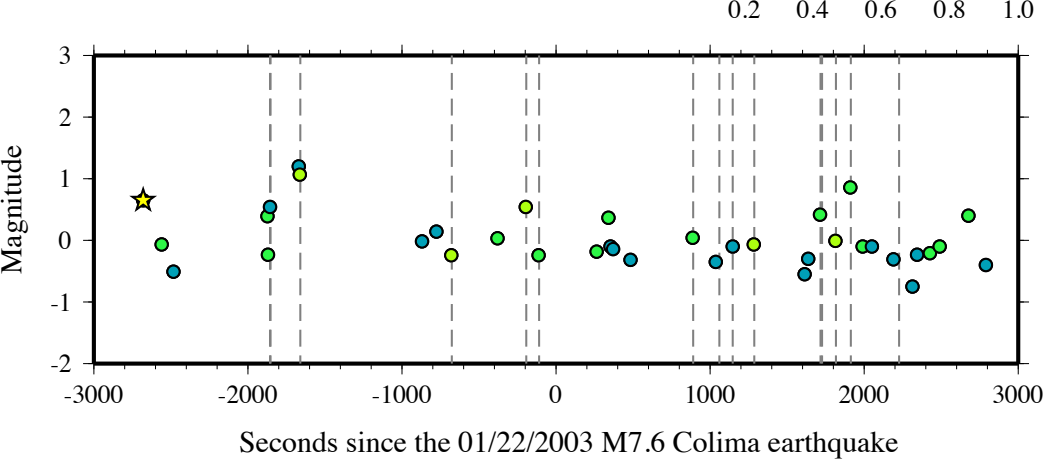

b

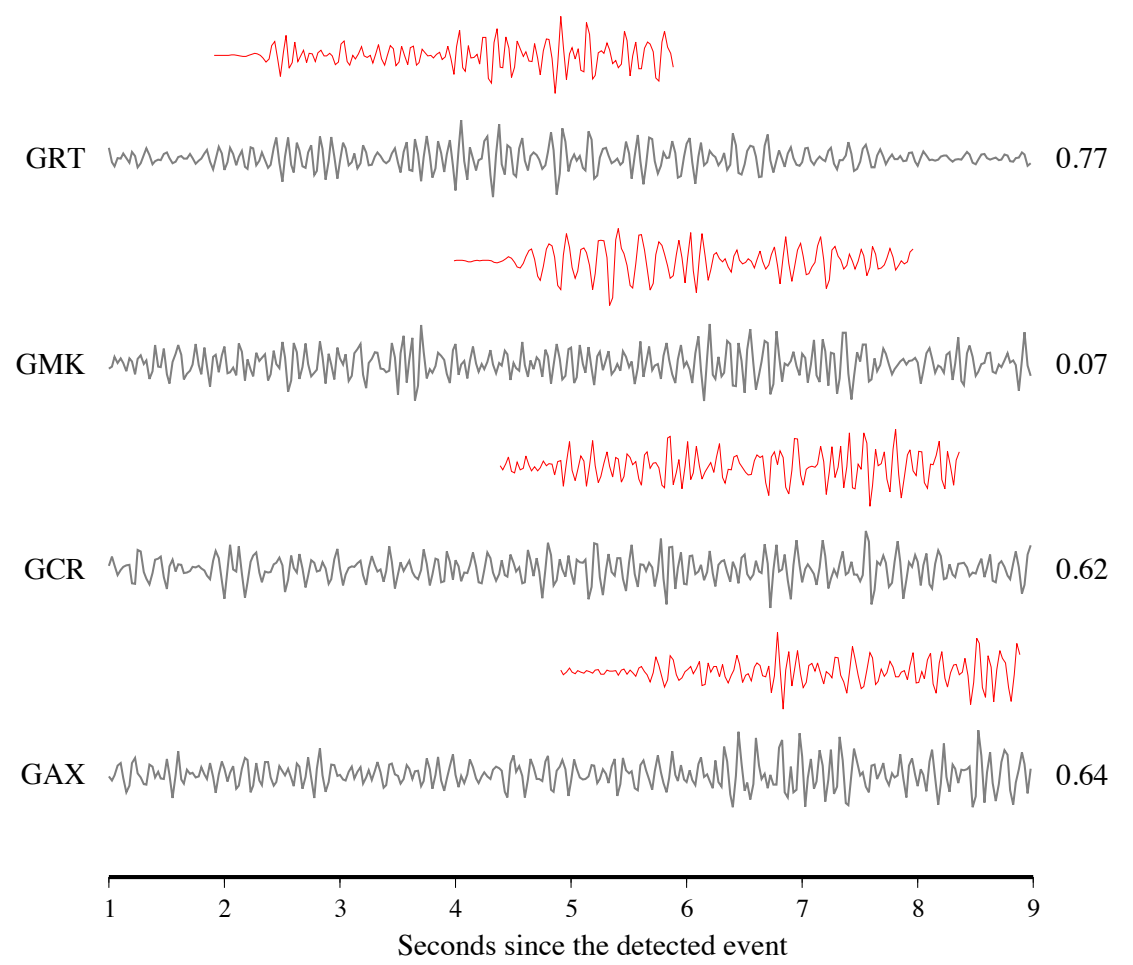

Figure S2. Example of small magnitude microearthquake detection. (a) Magnitude of microearthquakes detected around the time of the 01/22/2003 M7.6 Colima earthquake. Color indicates mean cross-correlation value from matched filter analysis. Gray dashed lines are times of events hand-picked by Aiken and Peng [2014]. (b) Gray and red waveforms are the continuous and template waveforms, respectively, for starred detected event in part (a). Station names are listed to the left of each continuous waveform. Cross-correlation values at each station are indicated on the right. 

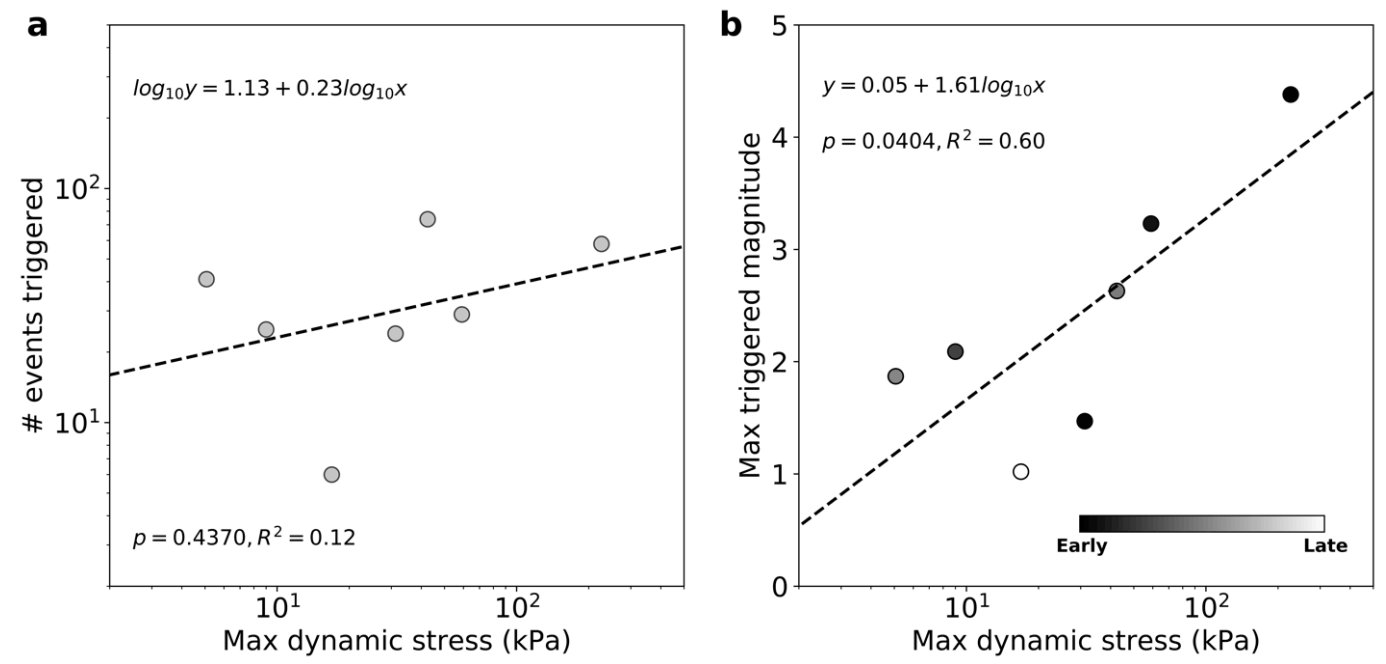

Figure S3. Same as Figure $2 \mathrm{~b}$ and 2c, except when using matched filter catalogs made with a 12 $\mathrm{x}$ median absolute deviation threshold. 

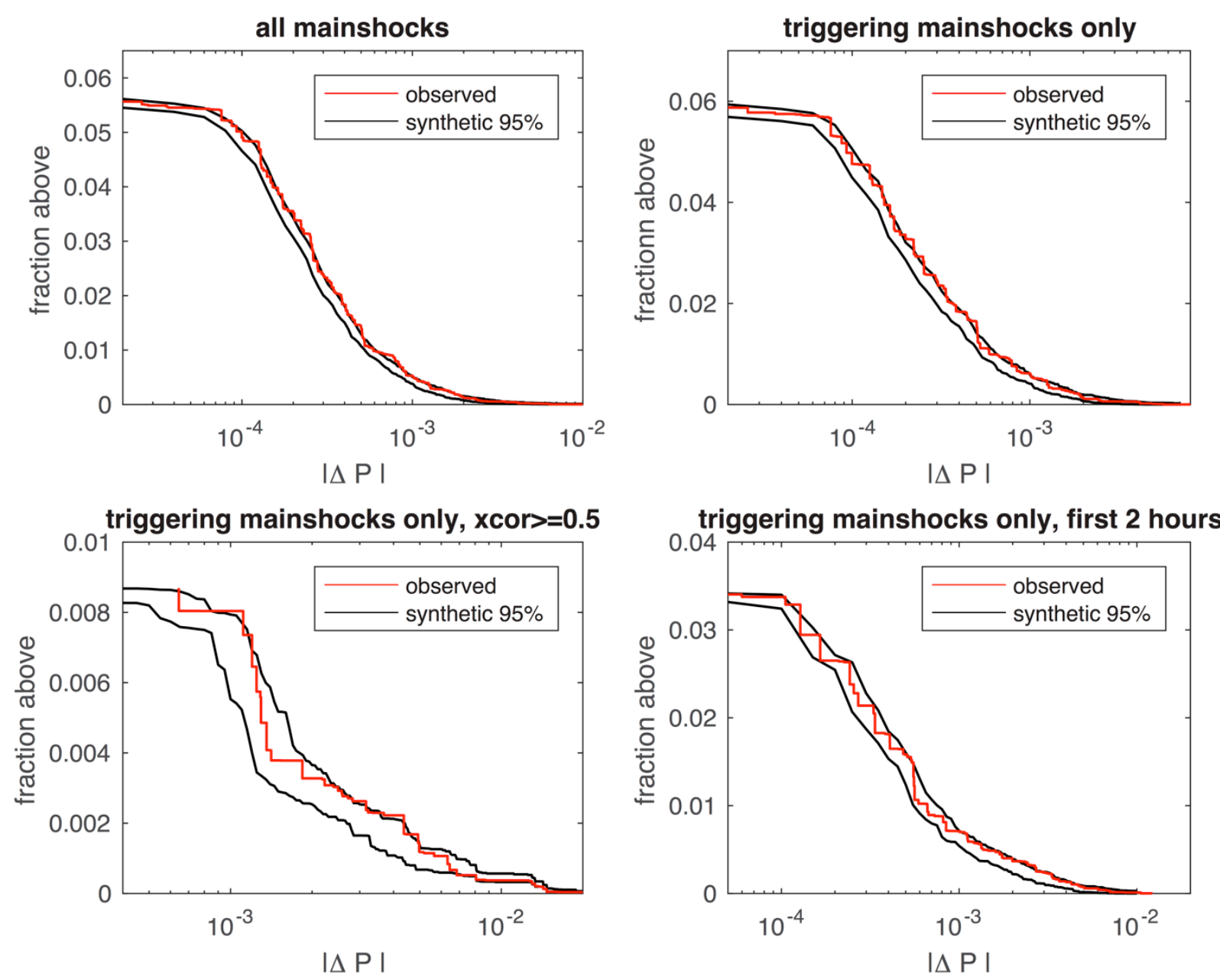

Figure S4. The change in the distribution of focal mechanisms before and after each mainshock, characterized as a joint $\mathrm{PDF}, \mathrm{P}(\theta, \varphi, \lambda)$, of the trend and plunge $(\theta, \varphi)$ of the normal to the nodal plane, and the corresponding rake, $\lambda$. The distribution change is expressed as $|\Delta \mathrm{P}|=\left|\mathrm{P}_{\text {post }}-\mathrm{P}_{\text {pre }}\right|$. The red curve shows the survival function of $|\Delta \mathrm{P}|$ for the observed events, while the black curves show the middle $95 \%$ of 1000 realization of reshuffling the data for each mainshock. The random reshufflings are meant to capture the values of $\Delta \mathrm{P}$ that can occur simply due to random chance, due to errors or unrelated fluctuations in the focal mechanism catalog. For each realization, we randomly assign events to the "pre-mainshock" and "post-mainshock" sets, retaining the original number of events in each set. We compute $|\Delta \mathrm{P}|$ for each realization in the same way it is computed for the real data. The fractions are small because $|\Delta \mathrm{P}|=0$ for most $(\theta, \varphi, \lambda)$. (a) A stack of results for all mainshocks. (b) A stack for the significantly triggering mainshocks, those with $Z \geq 1.96$. (c) A stack for the significantly triggering mainshocks, including only detected events with cross-correlation values (xcor) $\geq 0.5$. (d) A stack for the significantly triggering mainshocks, including only post-mainshock events within the first 2 hours. 


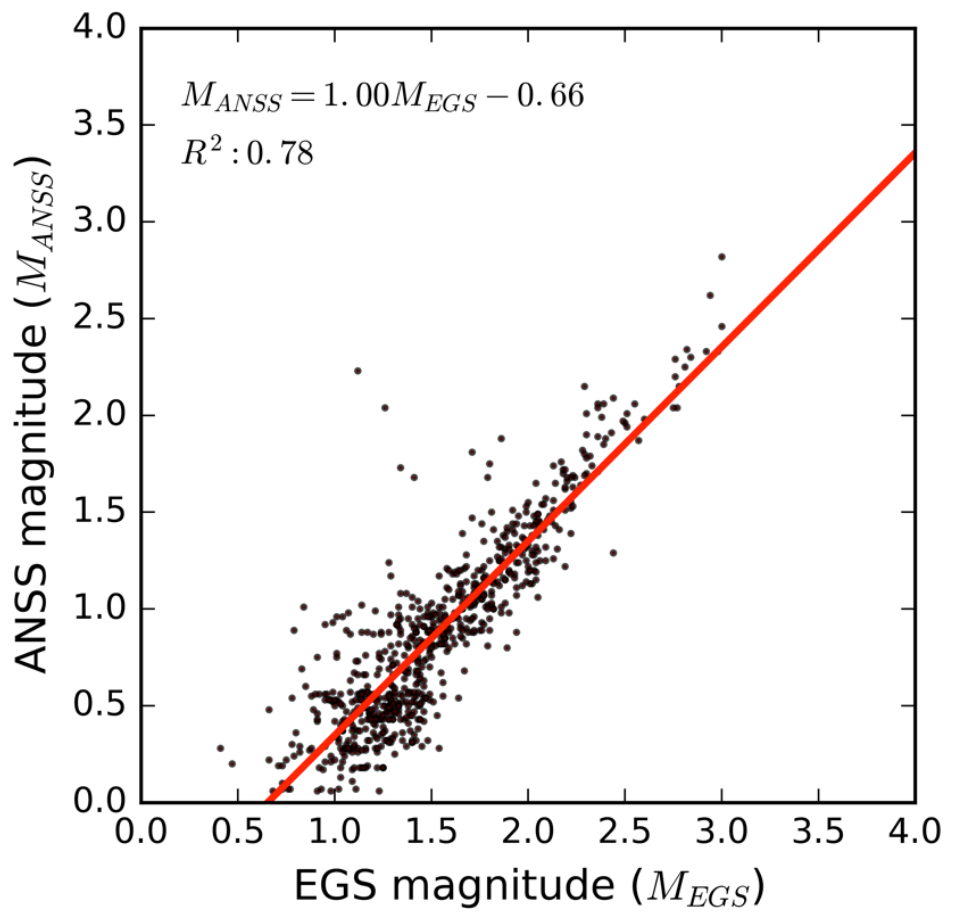

Figure S5. Linear regression fit for adjusting EGS magnitudes to ANSS magnitude scale. 


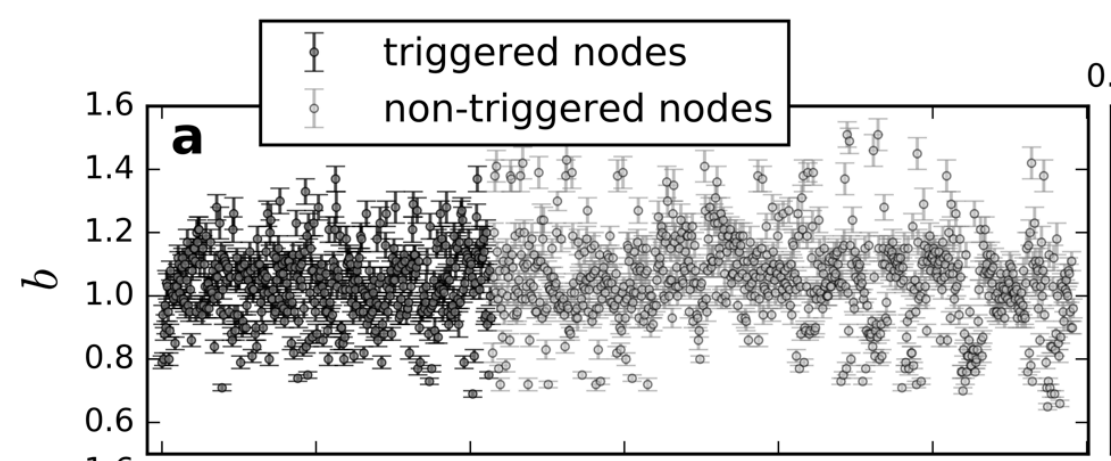

Normalized PDF

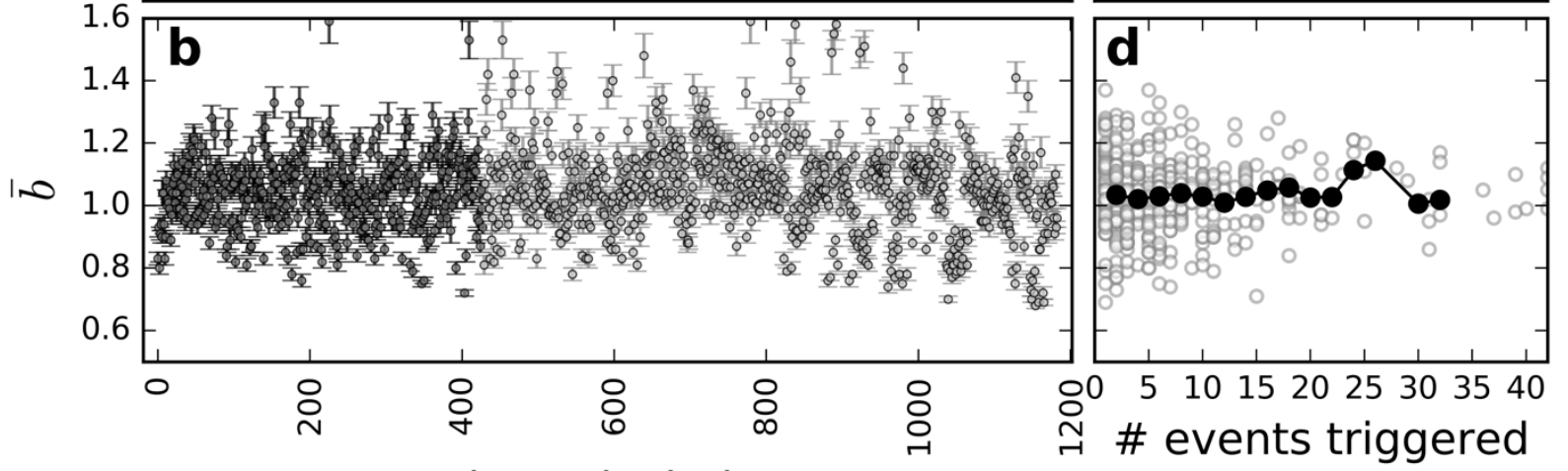

$b$-value calculation \#

Figure S6. Same as Figure 7 but for $0.02^{\circ}$ node spacing.

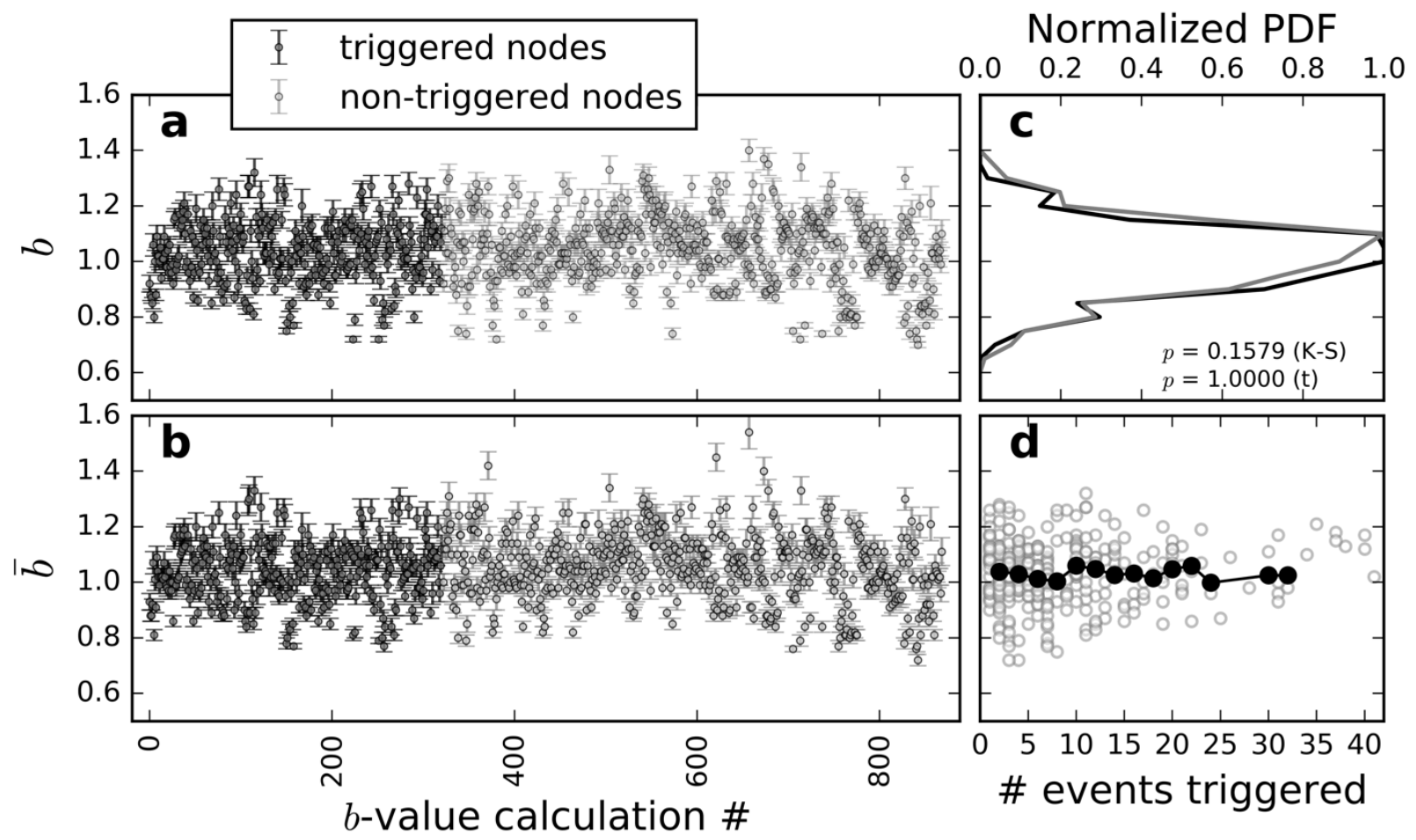

Figure S7. Same as Figure 7 but for $0.03^{\circ}$ node spacing. 


\section{Supplemental Tables}

Table S1. Seismic stations used for matched filter detection.

\begin{tabular}{cccc}
\hline Network & Station & Channels & Location \\
\hline NC & GAC & EHZ & $-122.8629,38.8727$ \\
NC & GAX/GAXB & EHZ & $-122.7573,38.7107$ \\
NC & GBG & EHZ & $-122.6826,38.8144$ \\
NC & GCR & EHZ & $-122.7172,38.7733$ \\
NC & GDX & EHZ & $-122.7953,38.8080$ \\
NC & GGP/GGPB & EHZ & $-122.8449,38.7646$ \\
NC & GMK & EHZ & $-122.7877,38.9696$ \\
NC & GPM & EHZ & $-122.9464,38.8450$ \\
NC & GRT & EHZ & $-122.6711,38.9387$ \\
NC & GSG & EHZ & $-122.7088,38.8663$ \\
NC & NHS & EHZ & $-122.6144,38.6565$ \\
NC & NMC & EHZ & $-122.9129,38.5910$ \\
NC & NMH & EHZ & $-122.6332,38.6694$ \\
NC & NMW & EHZ & $-122.7232,38.5504$ \\
NC & NSH & EHZ & $-122.6082,38.5199$ \\
\hline
\end{tabular}


Table S2. Template selection times by mainshock.

\begin{tabular}{|c|c|c|c|c|}
\hline Date & Time & Region & $M^{*}$ & $\begin{array}{c}\text { Template Selection } \\
\text { Window }\end{array}$ \\
\hline $1 / 13 / 2001$ & $13: 08: 42$ & offshore CA & 5.4 & $07 / 31 / 2000-07 / 13 / 2001$ \\
\hline $9 / 20 / 2001$ & $8: 02: 23$ & offshore CA & 5.1 & $04 / 05 / 2001-02 / 12 / 2002$ \\
\hline $6 / 23 / 2001$ & $20: 33: 14$ & southern Peru & 8.1 & $12 / 23 / 2000-11 / 28 / 2001$ \\
\hline $6 / 17 / 2002$ & $16: 55: 08$ & offshore CA & 5.2 & $03 / 05 / 2002-09 / 29 / 2002$ \\
\hline $11 / 3 / 2002$ & $22: 12: 42$ & Denali, AK & 7.9 & $07 / 30 / 2002-03 / 26 / 2003$ \\
\hline $1 / 22 / 2003$ & $2: 06: 35$ & Colima, MX & 7.6 & $09 / 20 / 2002-05 / 23 / 2003$ \\
\hline $8 / 15 / 2003$ & $9: 22: 15$ & offshore CA & 5.3 & $05 / 17 / 2003-12 / 20 / 2003$ \\
\hline $6 / 15 / 2005$ & $2: 50: 54$ & offshore CA & 7.2 & $05 / 12 / 2005-07 / 21 / 2005$ \\
\hline $1 / 4 / 2006$ & $8: 32: 32$ & Gulf of CA & 6.6 & $11 / 01 / 2005-03 / 08 / 2006$ \\
\hline $7 / 19 / 2006$ & $11: 41: 43$ & offshore CA & 5.0 & $06 / 19 / 2006-09 / 01 / 2006$ \\
\hline $1 / 13 / 2007$ & $4: 23: 21$ & Kuril Islands & 8.1 & $11 / 02 / 2006-05 / 04 / 2007$ \\
\hline $2 / 26 / 2007$ & $12: 19: 55$ & offshore CA & 5.4 & $11 / 17 / 2006-06 / 15 / 2007$ \\
\hline $5 / 9 / 2007$ & $7: 50: 04$ & offshore CA & 5.2 & $01 / 18 / 2007-08 / 10 / 2007$ \\
\hline $6 / 25 / 2007$ & $2: 32: 25$ & offshore CA & 5.0 & 03/05/2007-09/09/2007 \\
\hline $4 / 30 / 2008$ & $3: 03: 07$ & offshore CA & 5.4 & $03 / 17 / 2008-06 / 30 / 2008$ \\
\hline $8 / 3 / 2009$ & $17: 59: 56$ & Baja CA & 6.9 & $06 / 07 / 2009-10 / 07 / 2009$ \\
\hline $1 / 10 / 2010$ & $0: 27: 39$ & offshore CA & 6.5 & $11 / 29 / 2009-02 / 17 / 2010$ \\
\hline $2 / 4 / 2010$ & $20: 20: 22$ & offshore CA & 5.9 & $12 / 26 / 2009-03 / 08 / 2010$ \\
\hline $2 / 27 / 2010$ & $6: 34: 12$ & Maule, Chile & 8.8 & $01 / 27 / 2010-04 / 01 / 2010$ \\
\hline $4 / 4 / 2010$ & $22: 40: 42$ & Baja CA & 7.2 & $03 / 02 / 2010-05 / 07 / 2010$ \\
\hline $2 / 13 / 2012$ & 21:07:03 & offshore CA & 5.6 & $01 / 24 / 2012-03 / 07 / 2012$ \\
\hline $7 / 21 / 2012$ & $1: 52: 02$ & offshore CA & 5.1 & $06 / 16 / 2012-08 / 30 / 2012$ \\
\hline $3 / 10 / 2014$ & $5: 18: 13$ & offshore CA & 6.8 & $02 / 09 / 2014-04 / 10 / 2014$ \\
\hline $8 / 24 / 2014$ & $10: 20: 44$ & Napa, CA & 6.0 & $07 / 18 / 2014-10 / 07 / 2014$ \\
\hline $1 / 1 / 2015$ & $12: 16: 15$ & offshore CA & 5.3 & $11 / 27 / 2014-02 / 07 / 2015$ \\
\hline $1 / 28 / 15$ & $21: 08: 54$ & offshore CA & 5.7 & $12 / 23 / 2014-02 / 26 / 2015$ \\
\hline
\end{tabular}

*Magnitude as listed in the ANSS/ComCat catalog. 
Table S3. $Z$ value comparison for varied detection threshold

\begin{tabular}{|c|c|c|}
\hline Mainshock Origin Time & $Z, 9 \times M A D *$ & $Z, 12 \times M A D *$ \\
\hline $06 / 23 / 200120: 33: 14$ & 7.3 & 6.0 \\
\hline 09/20/2001 08:02:23 & $\mathrm{n} / \mathrm{a}$ & $\mathrm{n} / \mathrm{a}$ \\
\hline 06/17/2002 16:55:08 & 2.6 & $\mathrm{n} / \mathrm{a}$ \\
\hline 11/03/2002 22:12:42 & 11.5 & 8.5 \\
\hline 01/22/2003 02:06:35 & 2.4 & $\mathrm{n} / \mathrm{a}$ \\
\hline 08/15/2003 09:22:15 & 1.3 & $\mathrm{n} / \mathrm{a}$ \\
\hline 06/15/2005 02:50:54 & 3.9 & 1.6 \\
\hline 01/04/2006 08:32:32 & 1.1 & $\mathrm{n} / \mathrm{a}$ \\
\hline 07/19/2006 11:41:43 & 0.5 & $\mathrm{n} / \mathrm{a}$ \\
\hline 01/13/2007 04:23:21 & 2.3 & 1.3 \\
\hline 02/26/2007 12:19:55 & 1.7 & $\mathrm{n} / \mathrm{a}$ \\
\hline 05/09/2007 07:50:04 & 1.2 & $\mathrm{n} / \mathrm{a}$ \\
\hline $06 / 25 / 200702: 32: 25$ & 2.1 & $\mathrm{n} / \mathrm{a}$ \\
\hline 04/30/2008 03:03:07 & $\mathrm{n} / \mathrm{a}$ & $\mathrm{n} / \mathrm{a}$ \\
\hline 08/03/2009 17:59:56 & 4.7 & 3.8 \\
\hline 01/10/2010 00:27:39 & 2.7 & 2.3 \\
\hline 02/04/2010 20:20:22 & 0.9 & $\mathrm{n} / \mathrm{a}$ \\
\hline 02/27/2010 06:34:12 & 4.6 & 4.8 \\
\hline 04/04/2010 22:40:42 & 6.8 & 5.0 \\
\hline 02/13/2012 21:07:03 & 1.2 & 1.0 \\
\hline 07/21/2012 01:52:02 & -5.6 & 0.2 \\
\hline 03/10/2014 05:18:13 & 3.9 & 1.2 \\
\hline 08/24/2014 10:20:44 & 10.4 & 7.2 \\
\hline 01/01/2015 12:16:15 & 1.0 & $\mathrm{n} / \mathrm{a}$ \\
\hline 01/28/2015 21:08:54 & $\mathrm{n} / \mathrm{a}$ & $\mathrm{n} / \mathrm{a}$ \\
\hline
\end{tabular}

$* \mathrm{MAD}=$ median absolute deviation 